\title{
Computational tools for the estimation of Factor of Safety and location of the critical failure surface for slopes in rock masses that satisfy the Hoek-Brown failure criterion
}

\author{
C Carranza-Torres University of Minnesota, USA \\ E Hormazábal SRK Consulting (Chile) S.A., Chile
}

\begin{abstract}
This paper presents dimensionless graphical representations, computer spreadsheets and regression analysis equations for the quick estimation of Factor of Safety (FS) and location of the critical failure surface for slopes excavated in rock masses that satisfy the Hoek-Brown failure criterion. The problem considered in this paper involves slopes with planar faces and arbitrary values of height and inclination angle, excavated in homogeneous, isotropic and dry rock masses with shear strength characterised by the Hoek-Brown failure criterion. To reduce the number of variables in the problem and to be able to present stability results in the most compact way possible, a transformation law for the Hoek-Brown failure criterion that considers the parameter ' $a$ ' to be equal to 0.5 is applied in the analysis. Development of the proposed tools involved computation of more than 60,000 selected cases of slopes using the Bishop method of slices in a commercial limit equilibrium software. Results obtained from the analysis are summarised in dimensionless graphical representations and an Excel workbook made freely available on the internet. Based on the results obtained from the limit equilibrium models, equations for the quick estimation of conservative measures of FS of slopes are provided. The various tools presented in this paper allow casting light into the problem of establishing mechanical similarity of slopes excavated in rock masses that satisfy the Hoek-Brown failure criterion, in regard to FS and position of the critical circular failure surface. To illustrate the application of the proposed computational tools, a practical example involving the analysis of the stability of a slope in an actual open pit mine is provided.
\end{abstract}

Keywords: slope stability, Factor of Safety, Hoek-Brown, rock mass, limit equilibrium, Bishop, method of slices, shear strength reduction technique

\section{Introduction}

Since its introduction in 1980, the Hoek-Brown failure criterion (Hoek \& Brown 1980, 1997, 2019) has gained wide popularity in rock engineering as a means of quantifying the shear strength of intact rock and rock masses. The rock engineering community quickly adopted this semi-empirical criterion for design and analysis of surface and underground excavations in rock because there were not (and there are still not) other simple and mechanically-based alternatives for quantifying reduction of shear strength of intact rock when rock mass jointing is accounted for.

The problem of determining the Factor of Safety (FS) and position of the critical failure surface of slopes in rock masses that satisfy the Hoek-Brown failure criterion is of major importance in the practice of rock slope engineering, with applications in both mining and civil engineering. For example, in the design and analysis of slopes in deep open pit mines, FS and critical failure surfaces commonly need to be determined at the overall slope scale or at the inter-ramp slope scale for sections at selected locations in the pit (e.g. Hoek \& Karzulovic 2000; Hormazabal et al. 2009; de Bruyn et al. 2013).

Several authors have studied the problem of determining the FS and location of the critical failure surface for slopes in rock masses that satisfy the Hoek-Brown failure criterion and have provided results in the form of dimensionless charts, e.g. Dawson et al. (2000); Li et al. (2008); Shen et al. (2013); Nekouei \& 
Ahangari (2013); Kotze \& Bosman (2015); Jiang et al. (2016); Sun et al. (2016); Xu et al. (2017). Most of the published dimensionless charts allow estimation of FS but not the position of the critical failure surface.

A paper published by the authors in a previous Slope Stability Conference in Sevilla, Spain (Carranza-Torres \& Hormazabal 2018) presented computational tools to estimate the FS and position of the assumed critical circular failure surface for slopes in rock masses that satisfy the Mohr-Coulomb failure criterion. The tools consisted of dimensionless charts, computer spreadsheets, and regression analysis equations, and were developed based on results obtained for thousands of slope models solved with the Bishop method of slices (Bishop 1955) and implemented in the commercial limit equilibrium software SLIDE (Rocscience Inc. 2018). The dimensionless representations of results in Carranza-Torres \& Hormazabal (2018) were based on the analysis and extension of 'circular' dimensionless charts originally presented in Hoek \& Bray (1974, 1977, 1981), and discussed in more recent books on rock slope engineering (e.g. Read \& Stacey 2009; Wyllie 2018).

This paper is intended as the extension of the work presented in Carranza-Torres \& Hormazabal (2018) for slopes in rock masses that satisfy the Hoek-Brown failure criterion (for brevity, in the remainder of this paper, such rock masses will be referred to simply as 'Hoek-Brown rock masses'). The slopes considered in this paper are assumed to be large enough so that the degree of jointing of the rock mass at the slope scale, justifies the application of the Hoek-Brown failure criterion, and the assumption of a circular (rotational type) of failure, as given by the software SLIDE (Hoek \& Brown 1980; Hoek \& Bray 1974, 1977, 1981). To avoid repetition, the discussion about the different available methods of slope stability analysis, and the reasons for adopting the Bishop limit equilibrium method for the developments presented in this paper are not included in this introduction section (the reader is instead referred to Carranza-Torres \& Hormazabal 2018). The structure of sections in this paper is similar to that in the mentioned publication from 2018. The sections that follow focus on highlighting particularities of implementing the Hoek-Brown failure criterion in slope stability analysis, and on extending the previous work to the case of slopes excavated in Hoek-Brown rock masses.

\section{Transformed version of the Hoek-Brown failure criterion}

In order to reduce the number of variables in the problem, and to be able to present compact representations of factors of safety and position of the assumed critical circular failure surface, this paper uses a dimensionless scaled form of the Hoek-Brown failure criterion that was originally proposed by Londe (1988). This scaling (or transformation) rule was later used by the first author of this paper to obtain a compact closed-form solution for the problem of determining the extent of failure and convergence of a circular tunnel in a rock mass that satisfies the Hoek-Brown failure criterion (Carranza-Torres \& Fairhurst 1999; Carranza-Torres \& Fairhurst 2000). The advantages of applying the transformation rule to the problem of slopes addressed in this paper will become evident in later sections.

Before discussing the scaled form of the Hoek-Brown failure criterion, it is important to review the non-scaled form and the way in which the different parameters in the failure criterion are defined in terms of others. These equations will be referred to in later sections of this paper.

According to Hoek \& Brown $(1980,1997,2019)$, the relationship between principal stresses at failure for a rock mass is given by the following equation:

$$
\sigma_{1}=\sigma_{3}+\sigma_{c i}\left(m_{b} \frac{\sigma_{3}}{\sigma_{c i}}+s\right)^{a}
$$

where:

$$
\begin{array}{ll}
\sigma_{1} & =\text { major principal stress. } \\
\sigma_{3} & =\text { minor principal stress. } \\
\sigma_{c i} & =\text { the unconfined compressive strength of the intact rock. } \\
m_{b}, s \text { and a } & =\text { dimensionless parameters of the rock mass. }
\end{array}
$$


According to latest revisions of the Hoek-Brown failure criterion (Hoek et al. 2002; Hoek \& Brown 2019), the parameters $m_{b}, s$ and $a$ are computed according to the following equations:

$$
\begin{gathered}
m_{b}=m_{i} e^{\left(\frac{G S I-100}{28-14 D}\right)} \\
s=e^{\left(\frac{G S I-100}{9-3 D}\right)} \\
a=\frac{1}{2}+\frac{1}{6}\left(e^{-G S I / 15}-e^{-20 / 3}\right)
\end{gathered}
$$

where:

$$
\begin{aligned}
m_{i}= & \text { a parameter obtained from triaxial testing of intact rock samples. } \\
G S I= & \text { geological strength index, a scalar value between } 0 \text { and } 100 \text { estimated from the degree of } \\
& \text { jointing and condition of the joint surfaces of the rock mass in the field. } \\
D= & \text { disturbance factor, another scalar value between } 0 \text { and } 1, \text { that applies to excavation of } \\
& \text { tunnels and slopes, and foundations in rock (Hoek \& Brown 2019). }
\end{aligned}
$$

This factor is estimated based on the expected damage of the rock mass surrounding the excavation, due to the excavation process itself (e.g. whether mechanised or by blasting). This factor is only applied to the damaged rock immediately behind the excavated surface, and it has no impact on the properties of the overall rock mass where a deep-seated failure surface would be located.

Although the Hoek-Brown failure criterion given by Equation 1 can be readily applied to the solution of problems that can be formulated mathematically in terms of principal stresses $\left(\sigma_{1}\right.$ and $\left.\sigma_{3}\right)$, the Hoek-Brown failure criterion sometimes needs to be expressed in terms of shear and normal stresses on the failure plane (these will be denoted as $\tau_{s}$ and $\sigma_{n}$, respectively). Such is the case of the slope problem considered in this paper, where the Bishop method of slices requires the Hoek-Brown failure criterion to be applied at discrete shear failure surfaces (i.e. at the base of the slices), which outline the overall critical failure surface considered for the slope. Another example where the relationship between stresses $\tau_{s}$ and $\sigma_{n}$ at failure is needed, involves the derivation of a closed-form solution for the problem of a slope failing according to a single planar surface that satisfies the Hoek-Brown failure criterion, as presented in a recent paper by Carter \& Carranza-Torres (2019).

There is no closed-form equation that allows the Hoek-Brown failure criterion with the parameter $a$ given by Equation 4 to be expressed in terms of the shear stress $\tau_{s}$ and the normal stress $\sigma_{n}$ on the failure plane (a closed-form solution exists only when $a=0.5$, as discussed in Carranza-Torres 2004). The relationship can only be expressed in implicit form using the Balmer (1952) equations. A detailed discussion of the application of these equations, including examples, can be found in Carranza- Torres (2004). In this paper, for simplicity, the relationship between shear and normal stresses is expressed by the following generic equation:

$$
\tau_{\mathrm{s}}=\mathrm{f}_{\mathrm{HB}}\left(\sigma_{\mathrm{n}}, \sigma_{\mathrm{ci}}, \mathrm{s}, \mathrm{a}\right)
$$

In Equation 5, $f_{H B}$ represents a function of the independent variable $\sigma_{n}$ that, according to Equation 1, also depends on the variables $\sigma_{c i}, s$ and $a$. When the parameter $a$ in Equation 1 is considered to be equal to 0.5 , a reasonable assumption for the case of fair to good quality rock masses with geological strength index (GSI) values above approximately 30, the Hoek- Brown failure criterion given by Equations 1 or 5 allows application of a convenient scaled form. This scaled form has been originally proposed by Londe (1988) and is discussed next.

Following the notation in Carranza-Torres (2004), the principal stresses $\sigma_{1}$ and $\sigma_{3}$ in Equation 1 (again, with $a=0.5$ ) can be operated on to give the dimensionless transformed principal stresses $S_{1}$ and $S_{3}$ as follows:

$$
\begin{aligned}
& S_{1}=\frac{\sigma_{1}}{m_{b} \sigma_{c i}}+\frac{s}{m_{b}^{2}} \\
& S_{3}=\frac{\sigma_{3}}{m_{b} \sigma_{c i}}+\frac{s}{m_{b}^{2}}
\end{aligned}
$$


Similarly, the shear and normal stresses $\tau_{s}$ and $\sigma_{n}$ in Equation 5 can be operated on to give the transformed dimensionless stresses $T_{s}$ and $S_{n}$ as follows:

$$
\begin{gathered}
T_{s}=\frac{\tau_{s}}{m_{b} \sigma_{c i}} \\
S_{n}=\frac{\sigma_{n}}{m_{b} \sigma_{c i}}+\frac{s}{m_{b}^{2}}
\end{gathered}
$$

Once stresses have been transformed as in Equations 6 to 9, Equation 1 can now be written as follows:

$$
\begin{gathered}
S_{1}=S_{3}+\sqrt{S_{3}} \\
T_{S}=F_{H B}\left(S_{n}\right)
\end{gathered}
$$

Equations 10 and 11 can be regarded as 'global' (i.e. that all rock masses will satisfy) dimensionless forms of the Hoek-Brown failure criterion.

Figures 1 and 2 illustrate the global (or generic) nature of the scaled form of the Hoek-Brown failure criterion introduced earlier. The diagrams in Figures $1 \mathrm{a}$ and $1 \mathrm{~b}$ represent failure envelopes and discrete points on the failure envelope, obtained with Equations 1 and 5, respectively. In Figure 1a, the horizontal and vertical axes correspond to the minor and major principal stresses, respectively, divided by the unconfined compressive strength of the rock. In Figure $1 \mathrm{~b}$, the horizontal and vertical axes correspond to the normal and shear stresses on the failure plane, respectively, again divided by the unconfined compressive strength of the rock. The three curves and the selected points on the curves in the diagrams in Figure 1 correspond to the same intact rock, but to rock masses with different values of GSI, i.e. rock masses with different degree of jointing. Figure 1 shows, as expected, that when the quality of the rock mass decreases (i.e. when GSI decreases), the strength of the rock mass decreases. The diagrams in Figures $2 a$ and $2 b$ are equivalent to those in Figures $1 a$ and $1 b$, respectively, but with axes representing transformed stresses, as given by Equations 6 to 9. In Figures 2a and $2 b$, the rock mass envelopes and selected points that correspond to the three different rock mass qualities have merged into the 'global' Hoek-Brown failure envelopes, defined by Equations 10 and 11, respectively.

a)

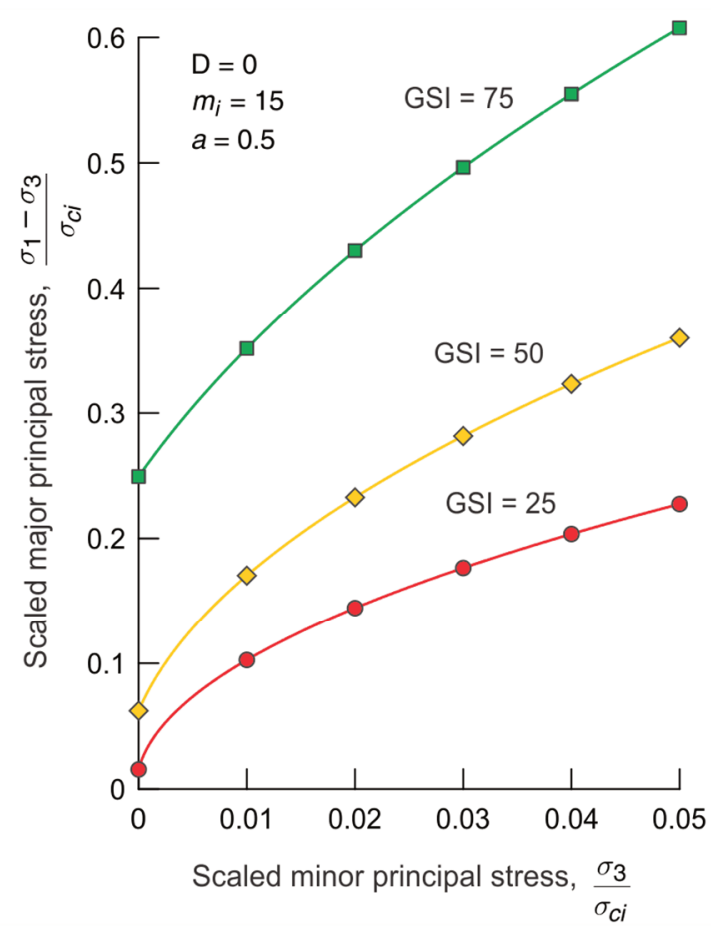

b)

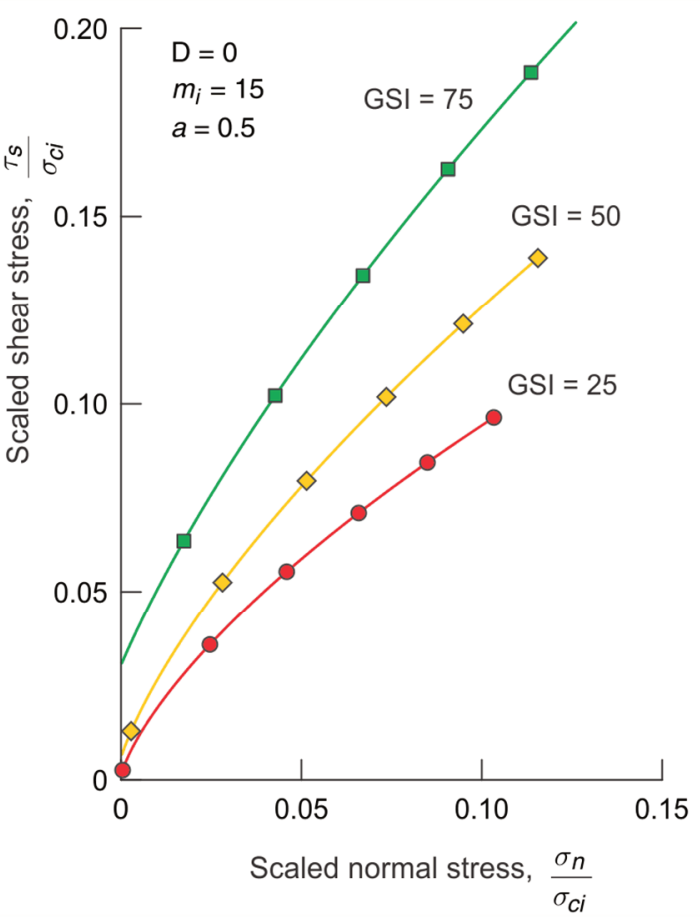

Figure 1 Diagrams representing shear strength of different rock masses satisfying the Hoek-Brown failure criterion. Failure envelopes in terms of (a) principal stresses and (b) shear and normal stresses on the failure plane, scaled with respect to the unconfined compressive strength of the intact rock 

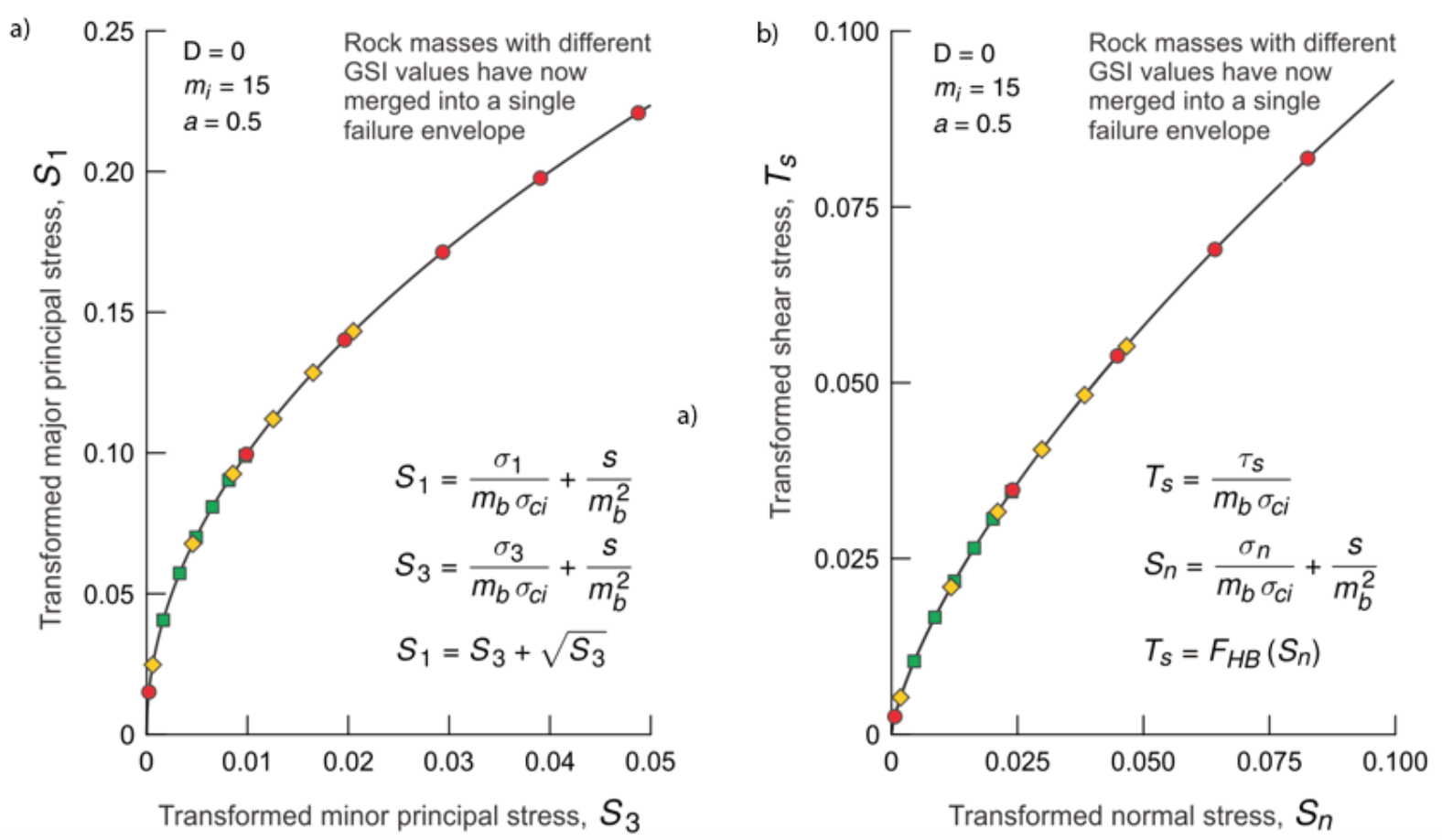

Figure 2 Diagrams equivalent to those represented in Figure 1, for the transformed Hoek-Brown failure criterion, according to Equations 6 to 11

\section{Definition of the slope problem}

The problem considered in this paper is shown in Figure 3. It involves a two-dimensional section of slope with inclination angle $\alpha$ and height $H$, excavated in an isotropic, homogeneous and dry rock mass of unit weight $\gamma$, that satisfies the Hoek-Brown failure criterion, with unconfined compressive strength $\sigma_{C}$, and Hoek-Brown parameters $m_{b}, s$ and $a$ (see Equations 2 to 4). To reduce the number of variables in the problem and to be able to apply the transformed version of the Hoek-Brown failure criterion introduced in Section 2, the Hoek-Brown parameter $a$ is considered to be 0.5 .

Referring to Figure 3 , the origin of a system of cartesian coordinates $(x . y)$ is assumed to be located at the toe of the slope (point $O$ in the figure). When the shear strength of the rock mass is affected by the $\mathrm{FS}$, the slope is assumed to be at a limit state of equilibrium with a critical assumed circular failure surface of radius $R$ and a centre of coordinates $x_{C}$ and $y_{c}$. The starting point of the failure surface (point $A$ in the figure) has coordinates $x_{A}$ and $y_{A}$, while the ending point of the failure surface (point $B$ in the figure) has coordinates $x_{B}$ and $y_{B}$. To simplify the problem, no explicit tension crack is considered for the failure surface.

For solving the problem, the most common definition of FS is adopted. This states that the FS is the ratio of the shear strength of the rock mass on the failure surface and the shear stress required for equilibrium (e.g. Abramson et al. 2002; Wyllie 2018). Of the various formulations available for computing the FS, the Bishop method of slices (Bishop 1955), as implemented in the commercial software SLIDE (Rocscience Inc. 2018) is employed in this study. The reader is referred to Carranza-Torres \& Hormazabal (2018) for details, including a discussion of the reasons why this method has been adopted in the study.

It must be emphasised that since the slope problem illustrated in Figure 3 involves a homogeneous rock mass, no distinction is made for the rock mass immediately (i.e. a few metres) behind the excavation surface. For slopes in large open pit mines, this rock mass is normally damaged due to blasting, and it has to be given a disturbance factor (D) different from zero (see, for example, Rose et al. 2018; Hoek \& Brown 2019). The various examples to be discussed in following sections assume a unique value of $D$ equal to zero that applies to the whole rock mass. 


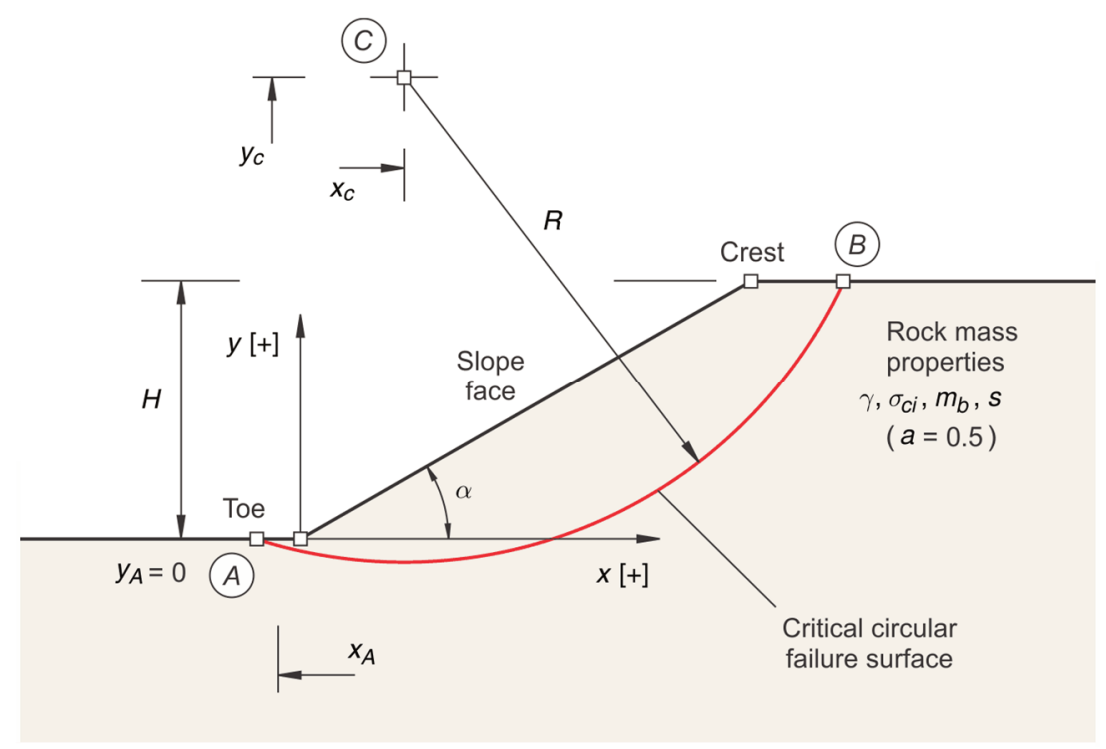

Figure 3 Cross-section of a planar slope excavated in a rock mass that satisfies the Hoek-Brown failure criterion

\section{$4 \quad$ Solution of the problem using the transformed Hoek-Brown failure criterion}

For the slope problem introduced in Figure 3, a characteristic measure of stress can be obtained by multiplying the unit weight of the rock mass $(\gamma)$ and the height of the slope $(H)$. This characteristic stress can be transformed using the same rule introduced in Section 2 (Equations 6 and 7) to give a dimensionless factor that will be referred to as $\mathrm{X}$ :

$$
X=\frac{\gamma H}{m_{b} \sigma_{c i}}+\frac{s}{m_{b}^{2}}
$$

As mentioned in Section 2, for slope problems solved with limit equilibrium methods, application of the Hoek-Brown failure criterion expressed in terms of shear and normal stresses on a failure plane is required. Comparing the definition of transformed shear stress $\left(T_{S}\right)$ and transformed normal stress $\left(S_{n}\right)$ in Equations 8 and 9 , respectively, the difference is in the term $\mathrm{s} / \mathrm{m}_{b}^{2}$; this term will be referred to as the dimensionless factor $Y$ :

$$
Y=\frac{s}{m_{b}^{2}}
$$

When the dimensionless transformed version of the Hoek-Brown failure criterion presented in Section 2 is applied to the slope problem in Figure 3, dimensional analysis shows that the FS of the slope must depend on the factors $X$ and $Y$, and the slope angle $(\alpha)$ only (for a demonstration, the reader is referred to Carranza-Torres 2004). The relationship can be written as follows:

$$
F S=\mathrm{f}_{F S}(X, Y, \alpha)
$$

Similarly, the abscissa and ordinate of the centre of the circular failure surface and the starting point of the failure surface (points $C$ and $A$ in Figure 3 , respectively), when divided by the slope height $H$, must depend on the factors $X$ and $Y$ and the slope angle $\alpha$ only (Carranza-Torres 2004). The relationships can be written as follows:

$$
\begin{gathered}
\frac{\mathrm{x}_{c}}{H}=\mathrm{f}_{x_{c}}(X, Y, \alpha) \\
\frac{\mathrm{y}_{c}}{H}=\mathrm{f}_{y_{c}}(X, Y, \alpha) \\
\frac{\mathrm{x}_{A}}{H}=\mathrm{f}_{x_{A}}(X, Y, \alpha) \\
\frac{\mathrm{y}_{A}}{H}=0
\end{gathered}
$$


In Equations 14 to 18, $\mathrm{f}_{F S}, \mathrm{f}_{x_{c}}, \mathrm{f}_{y_{c}}, \mathrm{f}_{x_{A}}$ and $\mathrm{f}_{y_{A}}$ represent functions of the independent variables $X, Y$ and $\alpha$, that can be traced (i.e. constructed by discrete points) by solving a series of slope cases for properly chosen values of these variables, to yield general representations of factors of safety and scaled coordinates of the centre and starting point of the critical failure surface.

Once the functions in Equations 15 to 18 have been constructed, the scaled radius of the critical circular failure surface $(R / H)$ can also be computed as the distance between the points $C$ and $A$ in Figure 3:

$$
\frac{R}{H}=\sqrt{\left(\frac{x_{c}}{H}-\frac{x_{A}}{H}\right)^{2}+\left(\frac{y_{c}}{H}-\frac{y_{A}}{H}\right)^{2}}
$$

In addition, the coordinates of the ending point $B$ of the failure surface in Figure 3 can be defined as the intersection of the critical circular failure surface and the horizontal plane at the crest of the slope. To reconstruct the functions in Equations 14 to 19, the Bishop method of slices implemented in the limit equilibrium software SLIDE (Rocscience Inc. 2018) was employed. A total of 60,984 cases of slopes were set up and computed. The input variables in the models were chosen so to obtain 121 equally spaced (in logarithm base-10 scale) slope cases with the factor $X$ ranging between $10^{-4}$ and 100 . Also, cases were chosen to obtain a total of 14 values of the factor $Y$, with a minimum value of zero, followed by values of $1 \times 10^{-5}, 2.5 \times 10^{-5}$, $5.0 \times 10^{-5}, 1 \times 10^{-4}$, etc. up to a maximum value of 0.1 . The ranges of values for $X$ and $Y$ were selected by means a Monte-Carlo simulation that evaluated the expected ranges of factors $X$ and $Y$ for typical ranges of values of slope heights, unit weights and Hoek-Brown parameters encountered in the practice of rock slope engineering. More details on the mentioned Monte-Carlo simulation and on how the limit equilibrium models were set up and computed are provided in Appendix A.

Figures 4 and 5 show the graphical representation of the function $f_{F S}$ in Equation 14, as obtained with SLIDE, for values of the dimensionless factor $Y$ equal to $1.0 \times 10^{-2}, 1.0 \times 10^{-3}, 1.0 \times 10^{-4}$ and 0 , respectively. The diagrams define the relationship between the FS (vertical axis) and the dimensionless factor $X$ (horizontal axis) for different slope angles $\alpha$ (the various curves in the diagram). In Figures 4 and 5 , the small dots on the curves represent the actual SLIDE cases that were evaluated (as mentioned above, each dot actually corresponds to five different sets of randomly computed properties $H, \gamma, \sigma_{c i}, m_{b}$ and $s$ ).

It is important to notice that large values of factor $X$ in the horizontal axes in the diagrams correspond to weak rock masses, while small values of $X$ correspond to strong rock masses. Consequently, the values of FS that are read on the vertical axis decrease as the value of $X$ increases. It is also important to notice that the different sets of curves in Figures 4 and 5 are asymptotic to vertical lines corresponding to values $X=Y$. This means that the FS becomes infinite when $X \leq Y$. This is understood by the fact that in order to have $X \leq Y$, the term $\gamma \mathrm{H} /\left(\mathrm{mb} \sigma_{c i}\right)$ in Equation 12 must be zero or negative, and for this to occur, the height of the slope must be zero or negative, when all other variables in Equation 12 are larger than zero.

Comparing now the diagrams in Figures $4 a, 4 b$ and $5 a$ with the diagram in Figure $5 b$, as the dimensionless factor $Y$ decreases, the rock mass becomes weaker (the Hoek-Brown parameter $s$ acts as a 'cohesion' component in Equation 1). In this regard, for the case $Y=0$ (Figure 5b), the rock mass has zero unconfined compressive strength and therefore, the Hoek-Brown failure criterion predicts the lowest shear strength possible (in the Hoek-Brown failure criterion, the rock mass unconfined compressive strength, $\sigma_{\mathrm{cm}}$, can be obtained by making $\sigma_{3}=0$ in Equation 1, therefore, if $s=0$, then $\sigma_{\mathrm{cm}}=0$ ). Because of this, the diagram in Figure $5 b$ ( for $Y=0$ ) can be used to obtain a conservative measure of FS of slopes in Hoek-Brown rock masses, corresponding to the case in which rock masses do not have unconfined compressive strength.

For space reasons, only diagrams corresponding to dimensionless factors $Y$ equal to $1.0 \times 10^{-2}, 1.0 \times 10^{-3}$, $1.0 \times 10^{-4}$ and 0 are presented in this paper. Similar diagrams corresponding to other $Y$ values (as mentioned previously, $1 \times 10^{-1}, 5.0 \times 10^{-2}, 2.5 \times 10^{-2}, 1.0 \times 10^{-2}, 5.0 \times 10^{-3} \ldots 1.0 \times 10^{-5}$ and 0 ) have been constructed and are made available to the reader (see Section 9).

A multiple regression analysis of the dimensionless representation corresponding to $Y=0$ (Figure 5b) has also been carried out as part of this study. This regression analysis allowed finding equations to compute the 
FS for slopes characterised by arbitrary inclination angles between 20 and $70^{\circ}$, considering that the Hoek-Brown rock mass has values $s=0$ and $a=0.5$. As explained above, this assumption corresponds to the situation in which the rock mass unconfined compressive strength is equal to zero, and therefore the regression analysis equations provide the most conservative (i.e. safest) measure of the FS for slopes in Hoek-Brown rock masses. The derived equations, a discussion on the details of the derivation, and the differences in FS to expect for rock masses characterised by $s=0$ and $s \neq 0$ are provided in Appendix B.

For space reasons, no diagrams for the functions $f_{X_{C}}, f_{Y_{C}}, f_{X_{A}}$ and $f_{Y_{A}}$ (Equations 15 to 18) defining the scaled coordinates of the critical failure surface are provided in this paper. Nevertheless, these diagrams can be easily constructed using the Excel workbook discussed in Section 6.

To illustrate the application of Equations 14 to 18, the following case is considered:

- Height of slope, $\mathrm{H}=360 \mathrm{~m}$.

- Angle of slope, $\alpha=50^{\circ}$.

- Unit weight of the rock mass, $y=27 \mathrm{kN} / \mathrm{m}^{3}$.

- Intact rock unconfined compressive strength, $\sigma_{\mathrm{ci}}=77.7 \mathrm{MPa}$.

- Hoek-Brown parameters $\mathrm{m}_{\mathrm{b}}=1.2601, \mathrm{~s}=1.5893 \times 10^{-3}$ and $\mathrm{a}=0.5$.

For the given properties, application of Equations 12 and 13 yields characteristic factors $X=0.1$ and $Y=1 \times 10^{-3}$.

Applying Equations 14 to 18, by means of the Excel workbook to be described in Section 6, the following results are obtained:

- $\mathrm{FS}=2.01$ (see Point $\mathrm{E}$ in Figure 4b).

- Scaled abscissa of the centre of the critical failure surface, $x_{c} / H=-0.5758\left(x_{c}=-207.28 m\right.$ for $\left.H=360 m\right)$.

- Scaled ordinate of the centre of the critical failure surface, $y_{c} / H=1.6293\left(y_{c}=586.53 \mathrm{~m}\right.$ for $\left.\mathrm{H}=360 \mathrm{~m}\right)$.

- Scaled abscissa of the starting point of the critical circular failure surface, $x_{A} / H=0$ (the ordinate of the starting point of the critical failure surface is always zero).

- Scaled radius of the critical circular failure surface, $R / H=1.728(R=622.08 \mathrm{~m}$ for $\mathrm{H}=360 \mathrm{~m})$.

When the same slope case above is computed using the Excel workbook discussed in Section 6 , considering the Hoek-Brown parameter $s=0, F S=1.88$, and a drop of $6 \%$ in FS is observed with respect to the FS $=2.01$ for the originally given value $s=1.5893 \times 10^{-3}$ (compare the position of points $E$ and $E^{\prime}$ in Figures $4 b$ and $5 b$, respectively). Application of the regression analysis equations in Appendix $B$, valid for $s=0$, gives $F S=1.88$, which is the same value mentioned above obtained with the Excel workbook. Appendix $B$ discusses the expected differences in factors of safety when the Hoek-Brown parameter $s$ is assumed to be different from zero, as defined by Equation 3, and when assumed to be zero. 
a)

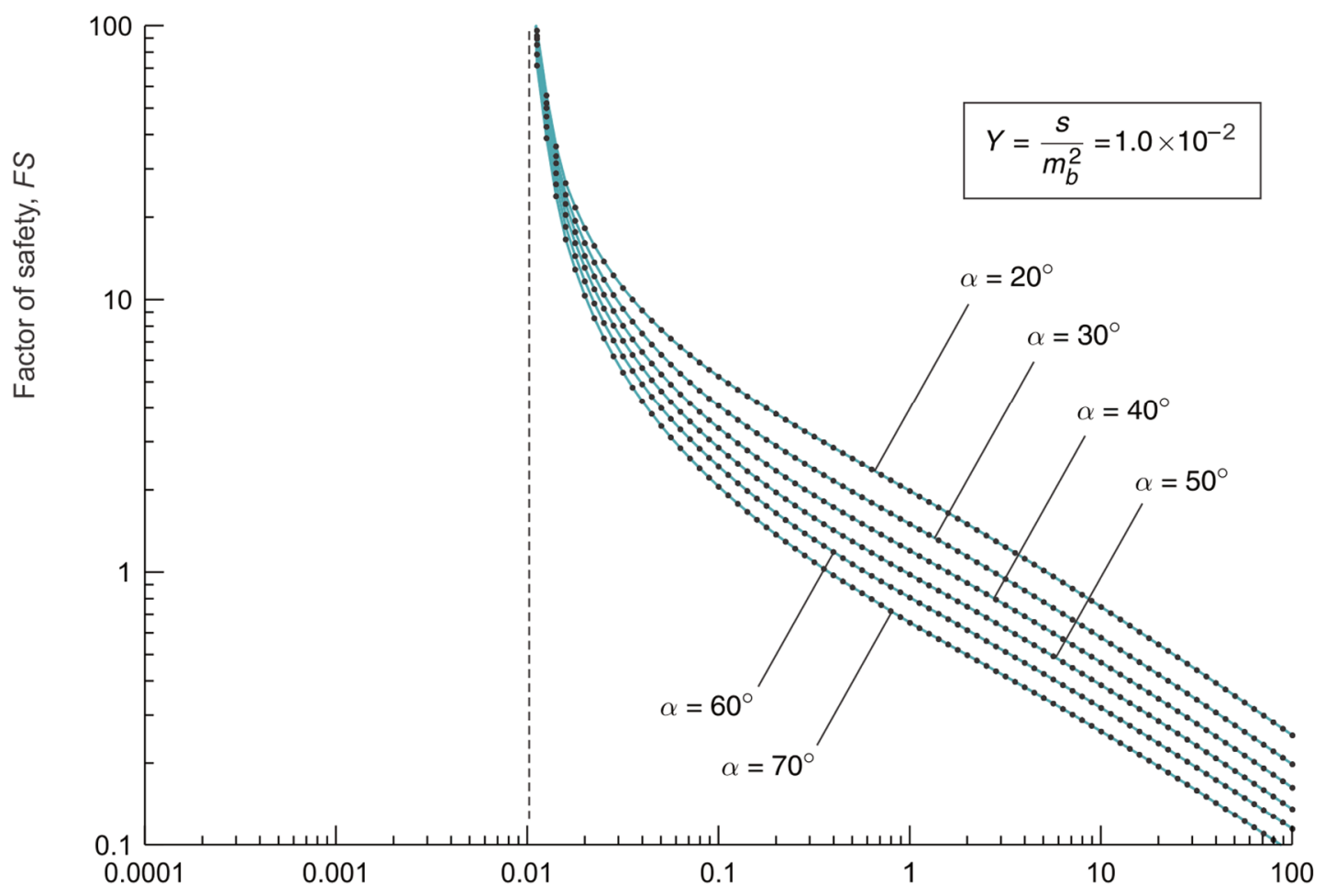

Stronger rock mass $\prec x=\frac{\gamma H}{m_{b} \sigma_{c i}}+\frac{s}{m_{b}^{2}} \Rightarrow \quad$ Weaker rock mass

b)

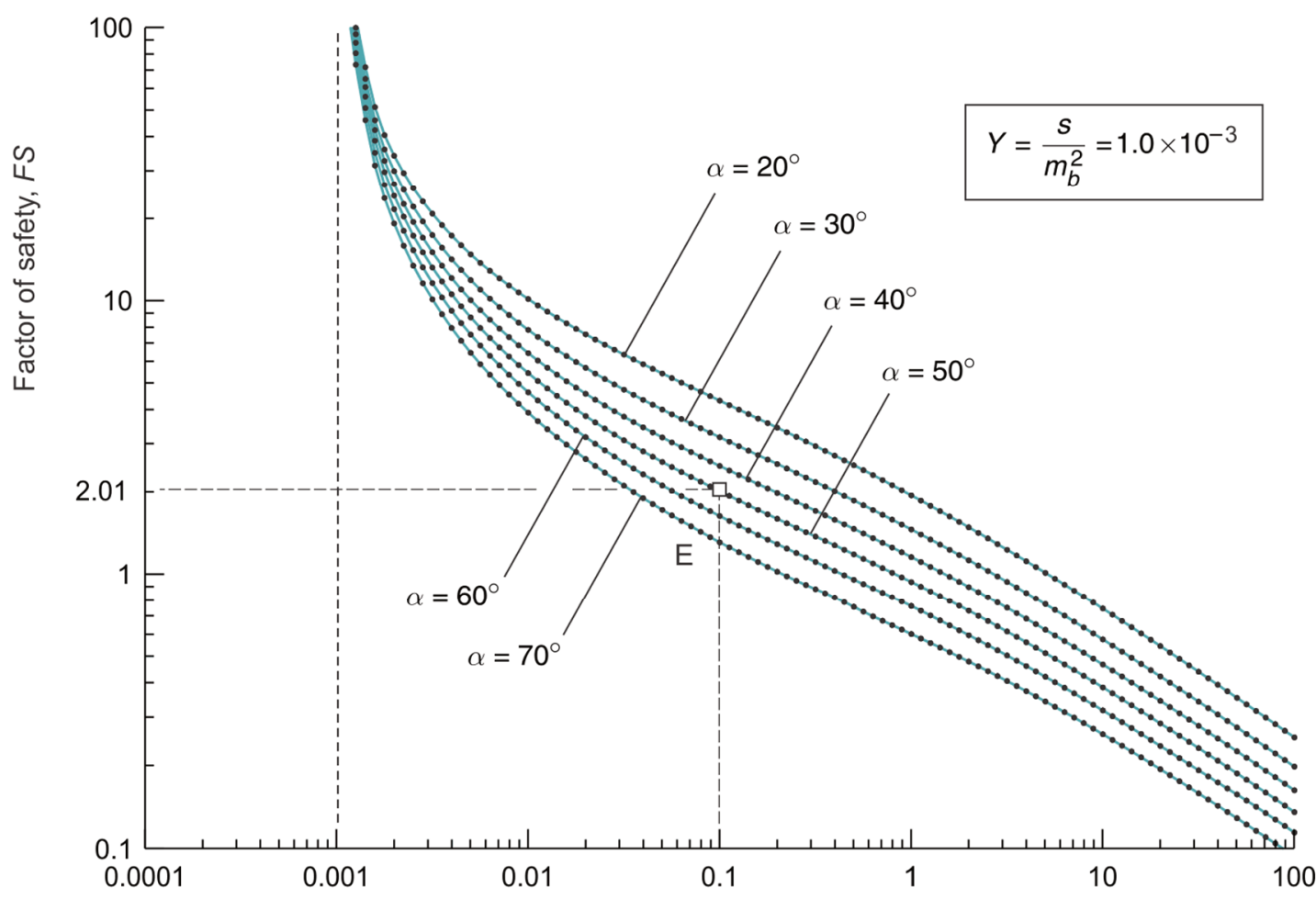

Stronger rock mass $\prec x=\frac{\gamma H}{m_{b} \sigma_{c i}}+\frac{s}{m_{b}^{2}} \Rightarrow$ Weaker rock mass

Figure 4 Dimensionless diagrams for the estimation of Factors of Safety for slopes of different inclination angles, for the dimensionless factor $Y$ (Equation 13) equal to (a) $1.0 \times 10^{-2}$; and (b) $1.0 \times 10^{-3}$, respectively 
a)

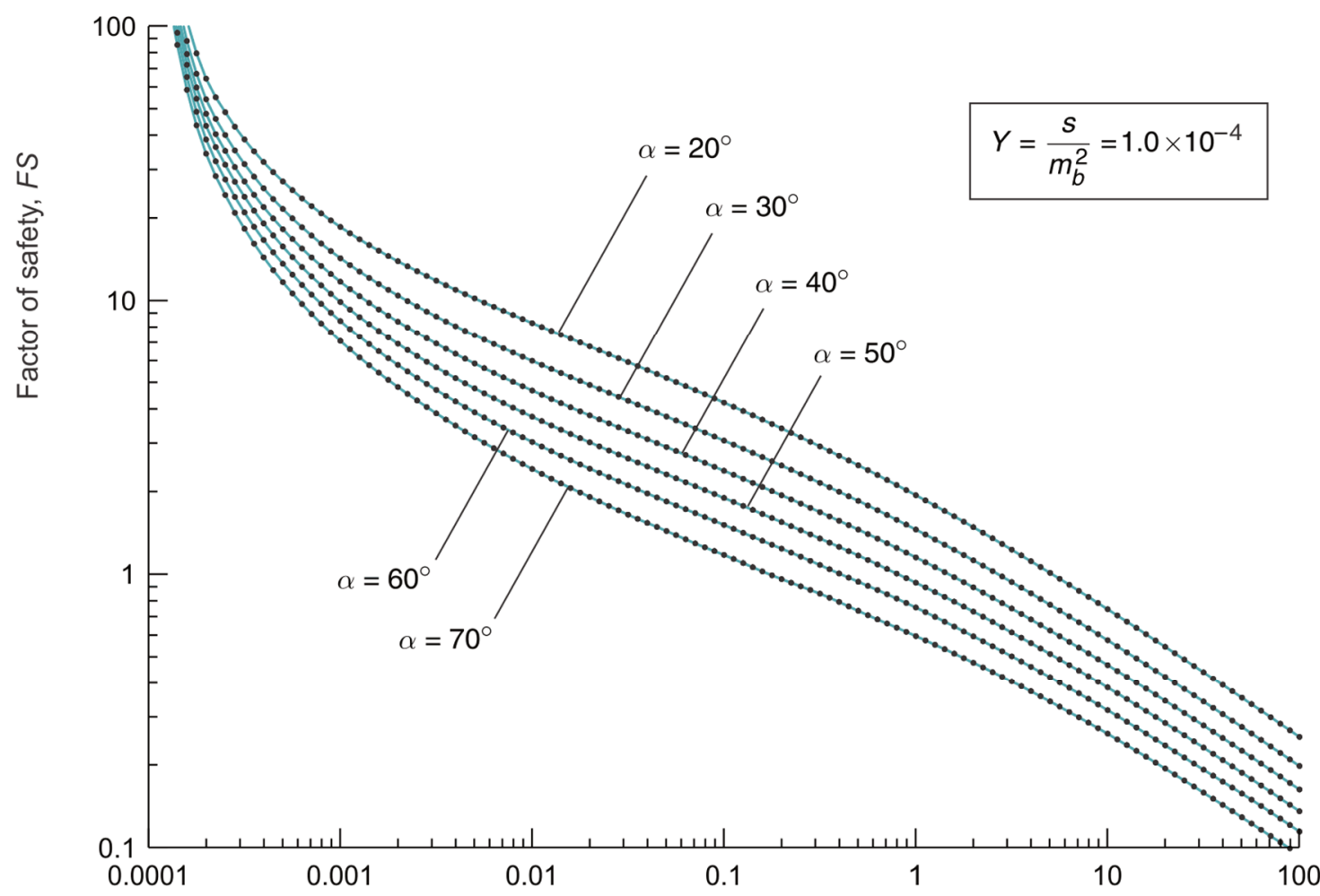

Stronger rock mass $\longleftarrow x=\frac{\gamma H}{m_{b} \sigma_{c i}}+\frac{s}{m_{b}^{2}} \quad \Longrightarrow \quad$ Weaker rock mass

b)

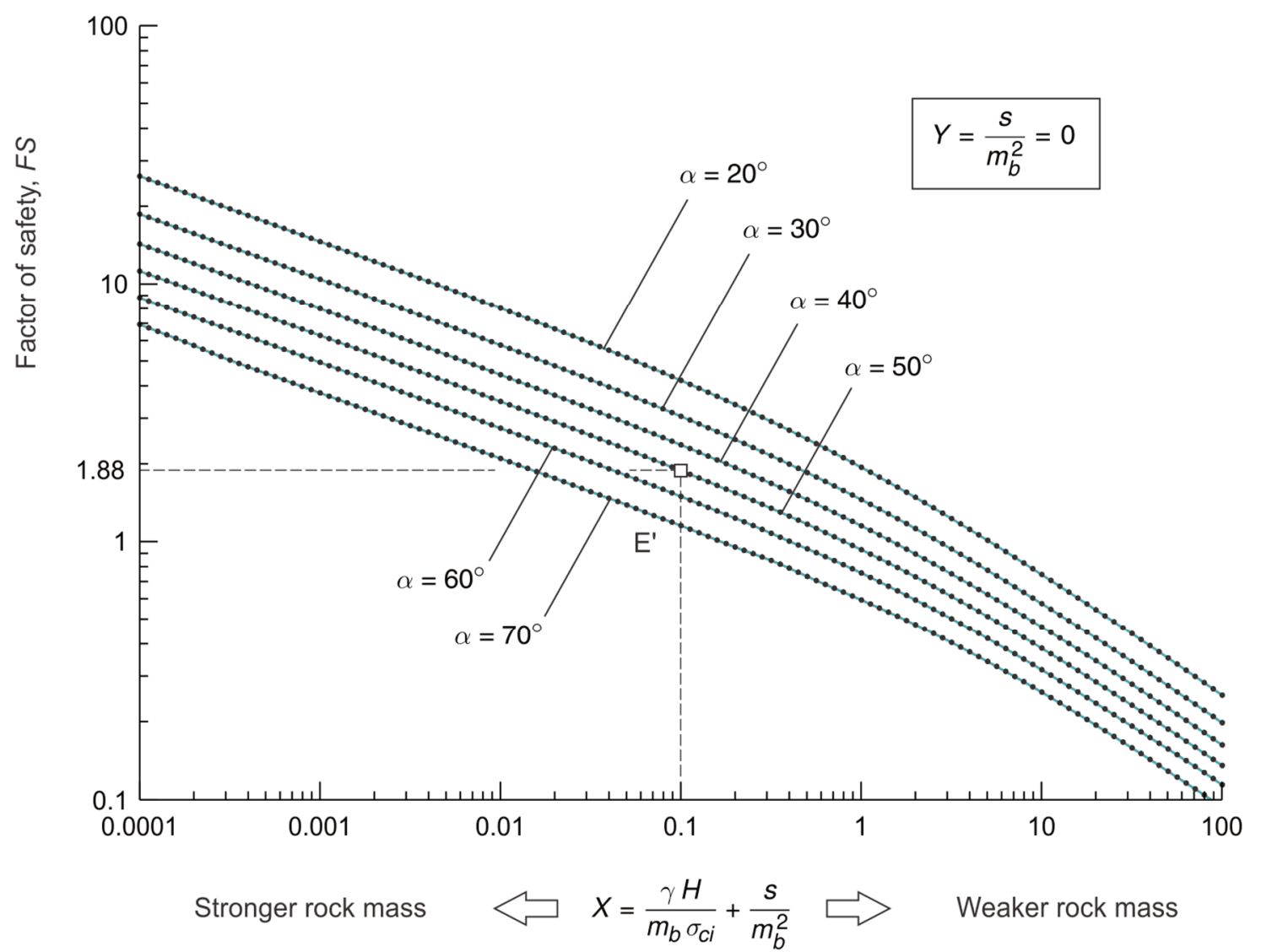

Figure 5 Dimensionless diagrams similar to those in Figure 4, for the dimensionless factor $Y$ equal to (a) $1.0 \times 10^{-4}$; and (b) 0 , respectively 


\section{Mechanical similarity of slope problems in Hoek-Brown rock masses}

The concept of mechanical similarity of slopes in Hoek-Brown rock masses was introduced in an earlier publication by the first author (Carranza-Torres 2004) and will be summarised here by means of slope examples.

Five different cases of slopes excavated in Hoek-Brown rock masses, as listed in Table 1, are considered (with the exception of Case 3, all other cases are hypothetical). Although the values of slope angle ( $\alpha$ ) listed in the table are the same for all cases, the values of height $(H)$, unit weight $(\gamma), G S I, D$, unconfined compressive strength $\left(\sigma_{c i}\right)$ and Hoek-Brown parameter $\left(\mathrm{m}_{\mathrm{i}}\right)$ are different. Consequently, the values of the Hoek-Brown parameters $\mathrm{mb}$ and $\mathrm{s}$ listed in the last two columns of Table 1, which are computed based on Equations 2 and 3 , are also different (the value of the Hoek-Brown parameter a is considered to be equal to 0.5 , as discussed already in Section 3).

At first sight and disregarding the fact that all five cases have the same slope angle $\left(\alpha=50^{\circ}\right)$, these correspond to quite different slopes excavated in Hoek-Brown rock masses. In particular, Case 3 in Table 1 corresponds to the example discussed in Section 4.

Considering now Table 2, all five cases are characterised by the same dimensionless factors $X=0.1$ and $Y=1 \times 10^{-3}$, given by Equations 12 and 13, respectively. Therefore, according to Equations 14 to 18 , all five cases are expected to have the very same values of FS and scaled coordinates of points that define the critical failure surface. Indeed, application of Equations 14 to 19, using the Excel workbook discussed in Section 6, yields the values of $F S$ and scaled coordinates of points $C$ and $A$ in Figure 3 , and the resulting scaled radius of the critical circular failure surface listed in the remaining columns of Table 2.

The fact that different combinations of input variables in the slope problem in Figure 3 can yield the very same values of dimensionless factors $X$ and $Y$ and therefore, the same values of $F S$ and scaled position of the critical failure surface implies that mechanical similarity of slopes in Hoek-Brown rock masses is controlled by the dimensionless factors $X$ and $Y$, and the slope angle $\alpha$.

The concept of mechanical similarity is further illustrated in Figures 6 and 7. These diagrams are equivalent to those in Figures 4 and 5, respectively. For clarity, curves corresponding to slope angles equal to 30,50 and $70^{\circ}$ only are included. The different sketches above the curves in Figures 6 and 7 correspond to slope cases in strong rock masses (characterised by an arbitrarily chosen value $X=0.001$, see points $A$ indicated the diagrams), in average rock masses (value $X=0.1$, points $B$ in the diagrams), and in weak rock masses (value $X=10$, points $C$ in the diagrams). The sketches show the position of the critical circular failure surface as obtained with the Excel workbook described in Section 6, for each of the six points in the diagrams in Figure 6 , and for each of the nine points in the diagrams in Figure 7. The sketches show that the failure surface tends to be deeper for lower slope angles and also deeper for weaker rock masses.

Finally, it should be noted that all five cases listed in Tables 1 and 2 plot as points B50 in Figure 6b. Therefore, the sketch corresponding to case $B_{50}$ in Figure $6 \mathrm{~b}$ is representative of the shape of the critical circular failure surface for all five cases listed in Tables 1 and 2. 
a)

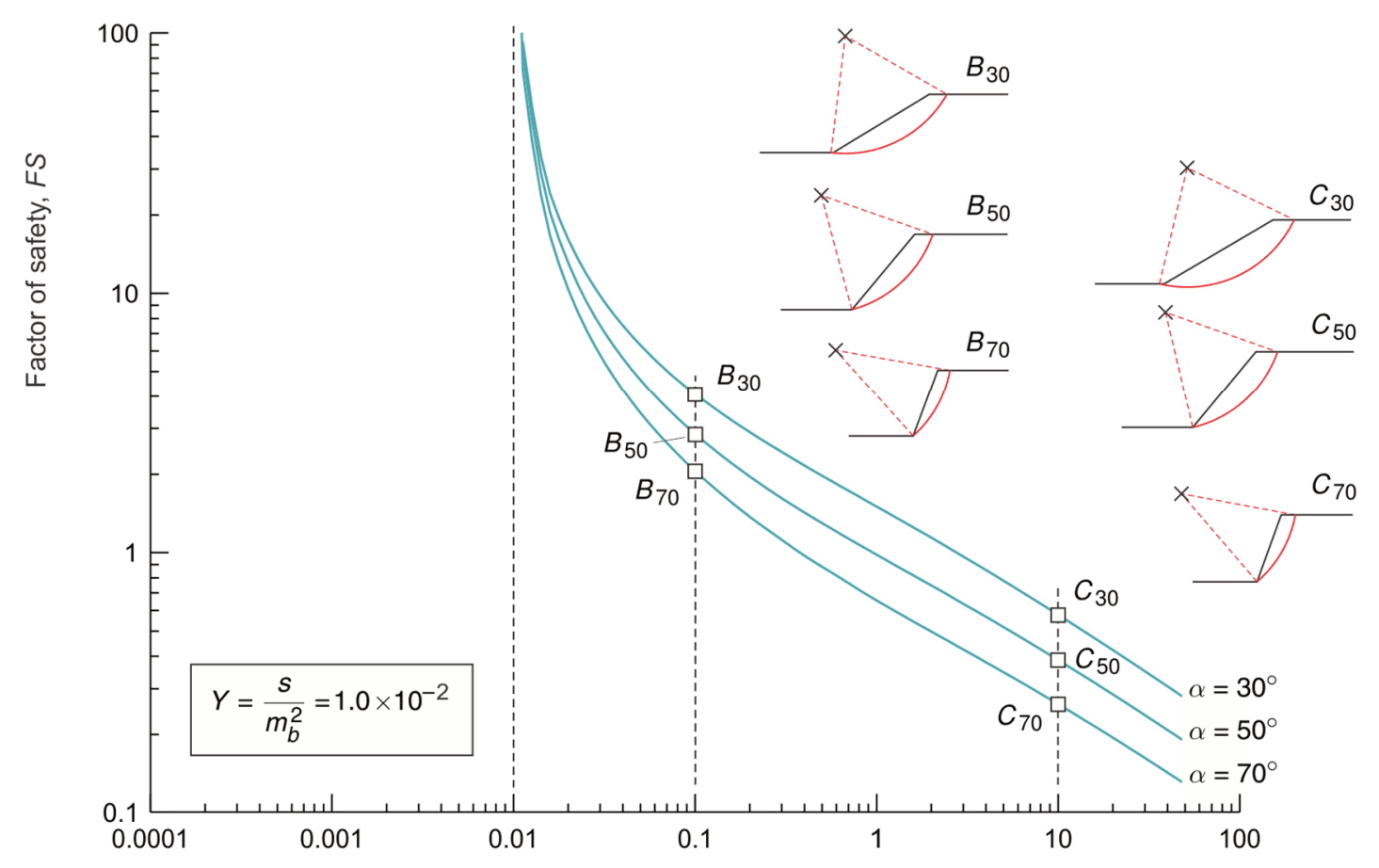

Stronger rock mass $\quad \longrightarrow=\frac{\gamma H}{m_{b} \sigma_{c i}}+\frac{s}{m_{b}^{2}}$

b)

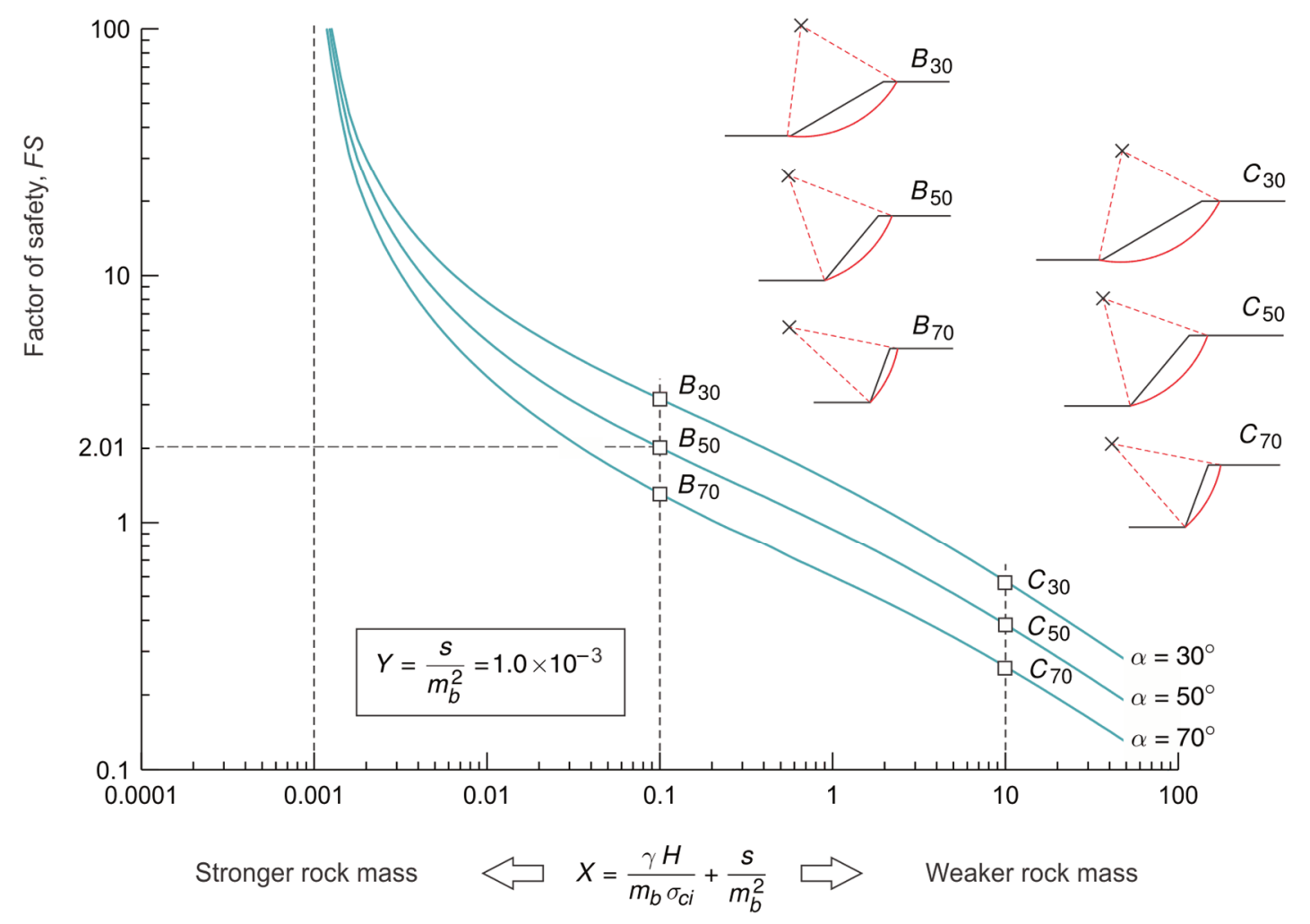

Figure 6 Dimensionless representations similar to those in Figure 4, including sketches showing the critical failure surfaces. All cases listed in Tables 1 and 2 , for which $X=0.1, Y=1 \times 10^{-3}$ and $\alpha=50^{\circ}$, correspond to point $B_{50}$ in the lower diagram 
a)

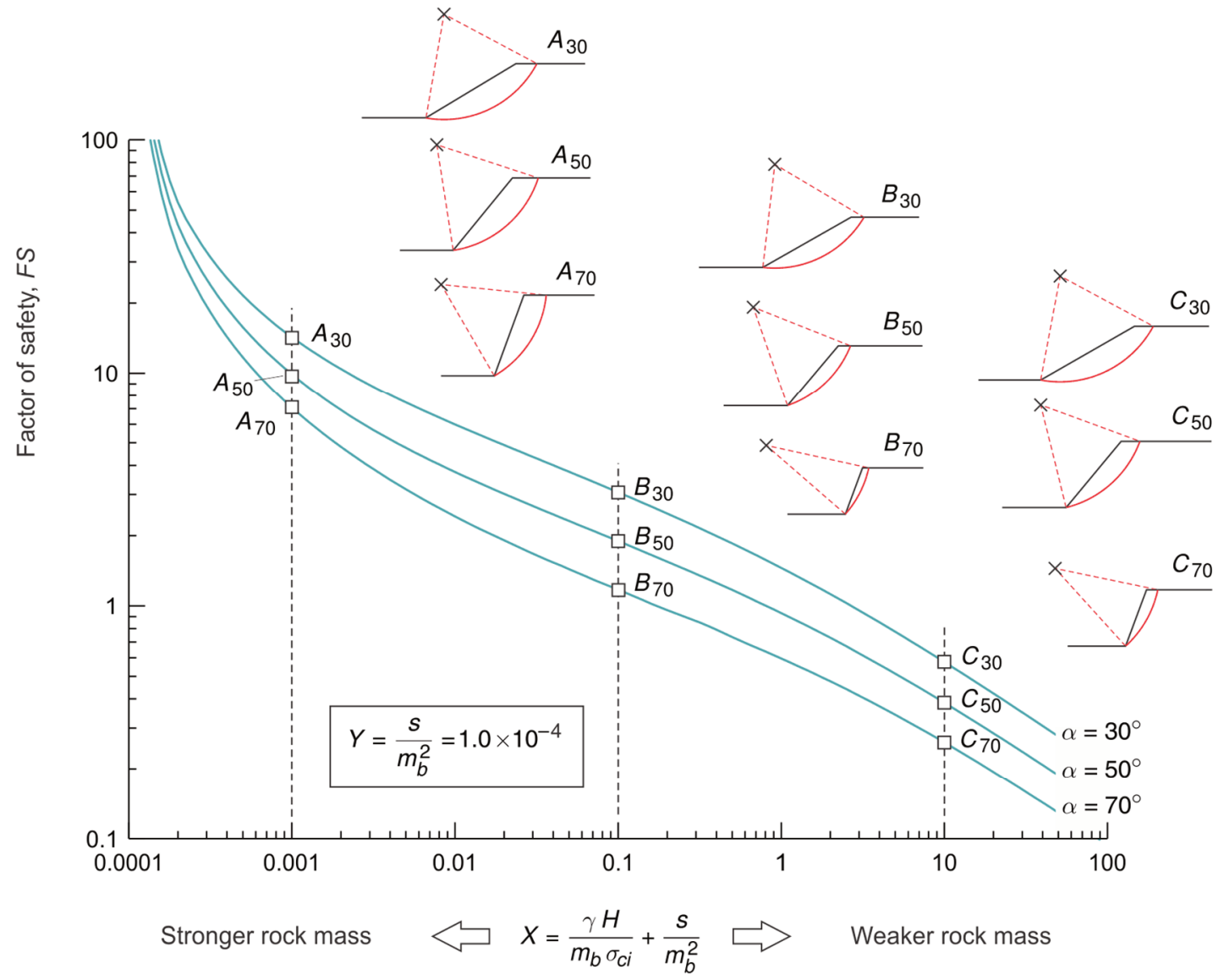

b)

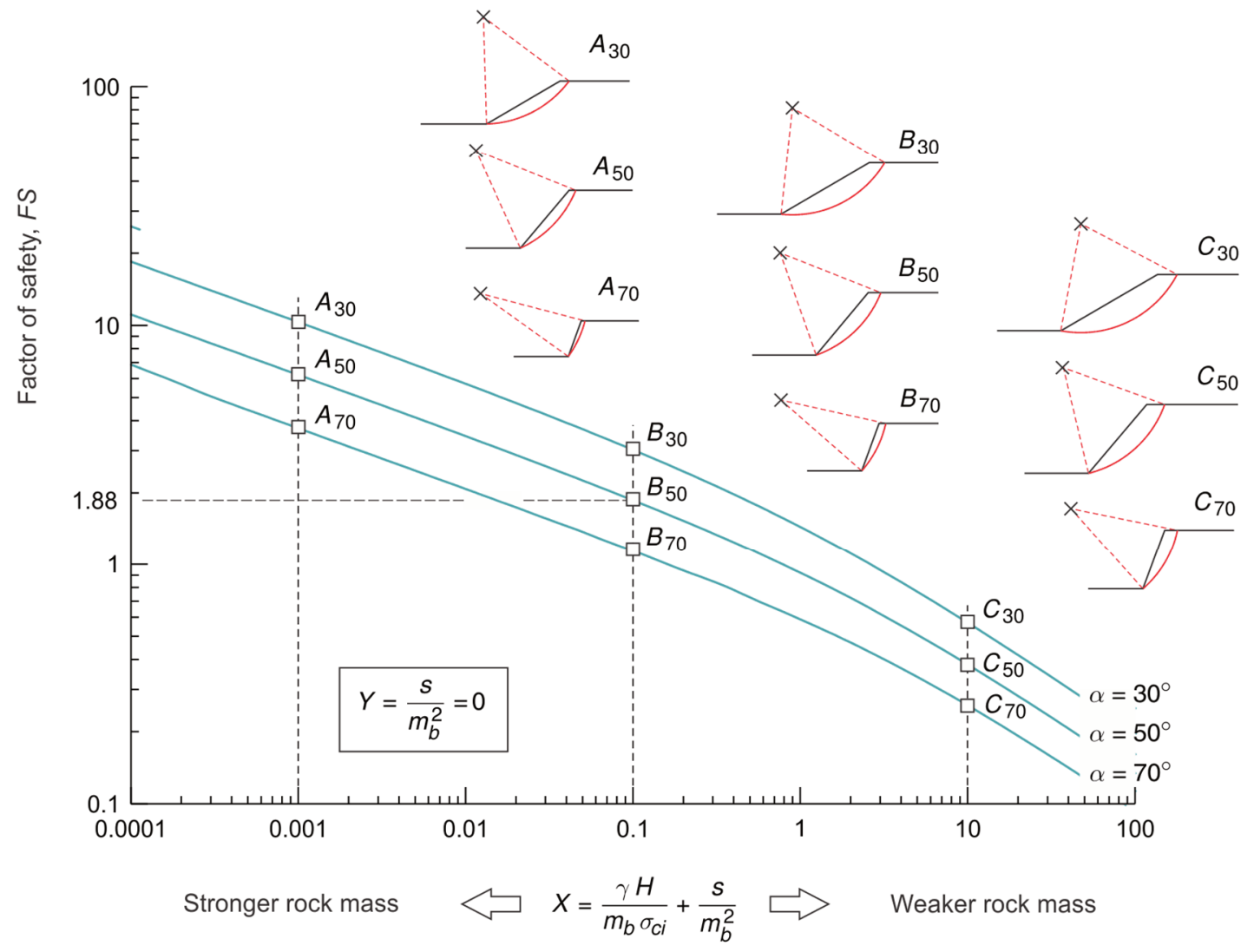

Figure 7 Dimensionless representations similar to those in Figure 5, including sketches showing the critical failure surfaces 
Table 1 Geometrical and mechanical properties of slope sections in five different open pit mines, all corresponding to an overall angle of $50^{\circ}$. In all listed cases, the disturbance factor $D$ is assumed to be zero and the Hoek-Brown parameter a is assumed to be 0.5

\begin{tabular}{lllllllll}
\hline Case & $\boldsymbol{\alpha}\left(\mathbf{(}^{\circ}\right)$ & $\mathbf{H}(\mathbf{m})$ & $\gamma\left(\mathbf{k N} / \mathbf{m}^{\mathbf{3}}\right)$ & $\mathbf{G S I}$ & $\boldsymbol{\sigma}_{\mathrm{ci}}(\mathrm{MPa})$ & $\mathbf{m}_{\mathrm{i}}$ & $\mathbf{m}_{\mathrm{b}}$ & $\mathbf{s}$ \\
\hline 1 & & 241 & 27 & 59 & 20.4 & 14 & 3.2374 & $1.0509 \times 10^{-2}$ \\
2 & & 520 & 25 & 77 & 15.0 & 20 & 8.7961 & $7.7649 \times 10^{-2}$ \\
3 & 50 & 360 & 27 & 42 & 77.7 & 10 & 1.2601 & $1.5893 \times 10^{-3}$ \\
4 & & 676 & 24 & 86 & 11.3 & 24 & 14.5567 & $2.1107 \times 10^{-1}$ \\
5 & 399 & 26 & 24 & 225 & 7 & 0.4638 & $2.1509 \times 10^{-4}$ \\
\hline
\end{tabular}

Table 2 Values of the dimensionless factors $X$ and $Y$ (Equations 12 and 13, respectively), FS and scaled coordinates that define the position of the critical circular failure surface for the cases in Table 1, as obtained with Equations 14 to 19, using the Excel workbook discussed in Section 6

\begin{tabular}{lllllllll}
\hline Case & $\mathbf{X}$ & $\mathbf{Y}$ & $\mathbf{F S}$ & $\mathbf{x}_{\mathrm{c}} / \mathbf{H}$ & $\mathbf{y}_{\mathbf{c}} / \mathbf{H}$ & $\mathbf{x}_{\mathrm{A}} / \mathbf{H}$ & $\mathbf{y}_{\mathrm{A}} / \mathbf{H}$ & $\mathbf{R} / \mathbf{H}$ \\
\hline 1 & & & & & & & & \\
2 & & & & & & & & \\
3 & 0.1 & $1 \times 10^{-3}$ & 2.01 & -0.5758 & 1.6293 & 0.0000 & 0.0000 & 1.7280 \\
4 & & & & & & & & \\
5 & & & & & & & & \\
\hline
\end{tabular}

\section{Computer spreadsheet for stability analysis}

Although dimensionless charts have been the traditional way of summarising and presenting results of stability analyses, in modern rock engineering design practice, engineers typically prefer the use of computer spreadsheets over the use of dimensionless charts (Hoek, pers. comm., 2000).

With this in mind, and based on Carranza-Torres \& Hormazabal (2018), the results of the Bishop limit equilibrium models that allowed the functions in Equations 14 to 17 to be reconstructed, have been summarised in an Excel workbook called 'Slope Stability Calculator for Slopes in Hoek-Brown rock masses' (see Figure 8). The Excel workbook implements a polynomial interpolation scheme that allows the user to obtain FS and locations of critical circular failure surfaces for any slope, provided that the values of dimensionless factors $X$ and $Y$, and the angle $\alpha$, fall within the ranges stated in Section 4.

The main interface in this Excel workbook is the worksheet called 'Main Page' shown in Figure 8a. This spreadsheet allows the user to enter the input data and to read the results. Application of this spreadsheet to compute FS and coordinates of points for the failure surface is straightforward, after reading the brief description next to the cells corresponding to input data and output results in the main spreadsheet. Referring to Figure 8a, if the cell 'Make a plot?' indicates 'yes', then a different spreadsheet called 'Plot' in the workbook provides a graphical representation of the slope case together with a summary of input data and results (see Figure 8b).

It must be emphasised that the Excel workbook does not include an implementation of the limit equilibrium method of slices to compute results of slope problems. Instead, the Excel workbook uses lookup table algorithms to interpolate results of models that have been already computed with the commercial limit equilibrium software SLIDE (Rocscience Inc. 2018). For efficiency in interpolating tables and to be able to generate the plot of the slope with a consistent scaling for both horizontal and vertical axes, the Excel workbook uses a visual basic for applications macro. Therefore, if asked by Excel, the user needs to allow the software to activate the macro for the workbook to work. 
Section 9 provides information on how the Excel workbook described in this section can be freely downloaded from the internet.

a)

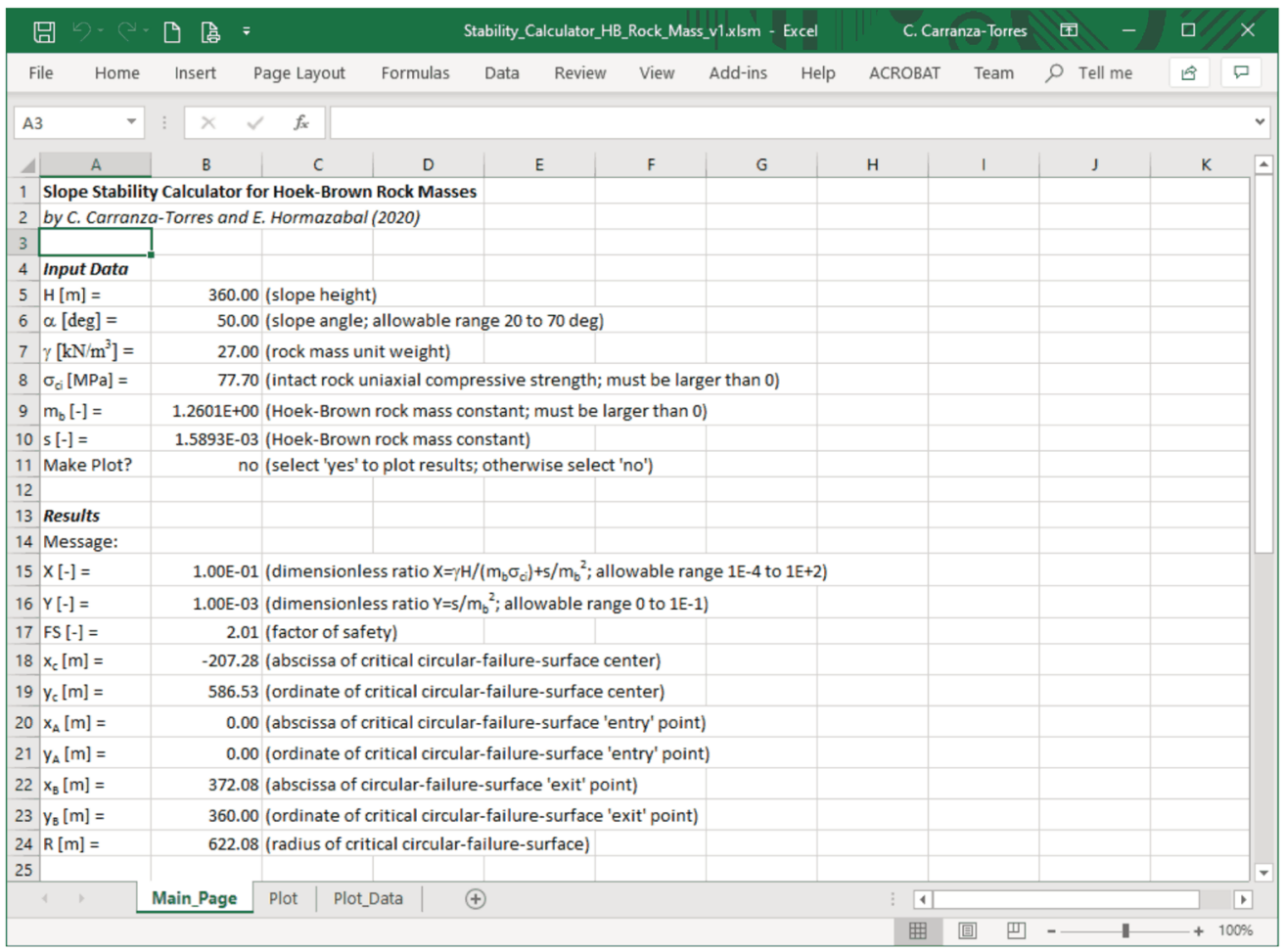

b)

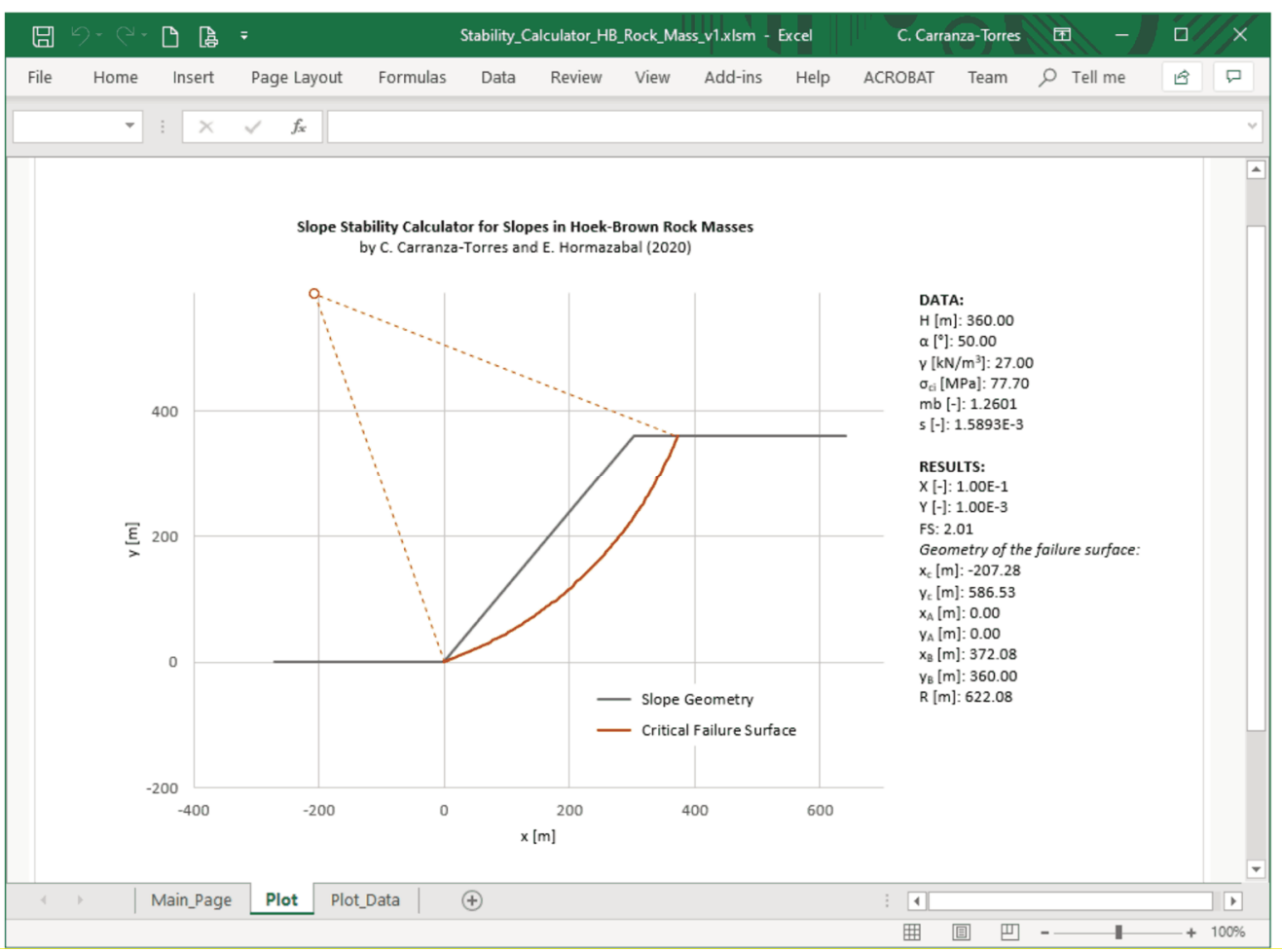

Figure 8 Excel workbook for implementation of stability computations. (a) Main worksheet; (b) Graphical representation of the slope problem

\section{$7 \quad$ Application example}

Figure 9 shows the view of a rock slope in a sector of an open pit mine in Chile that was analysed using the tools presented in previous sections. The slope has 12 benches with a bench height of $30 \mathrm{~m}$ and a bench 
width of $16 \mathrm{~m}$. The bench face angle is $71^{\circ}$. This results in a total slope height, $\mathrm{H}=360 \mathrm{~m}$, and an overall slope angle (measured from toe to crest), $\alpha=50^{\circ}$. For the open pit slope shown in Figure 9 , at the scale of the full height of the slope, the joint spacing is small enough relative to the slope height, that the assumption of ground continuity and isotropy can be considered valid and therefore the Hoek-Brown failure criterion can be applied (Hoek \& Brown 1980, 1997, 2019).

The rock mass, which has an average unit weight $y=27 \mathrm{kN} / \mathrm{m}^{3}$, is characterised by the following Hoek-Brown properties:

- $\mathrm{GSI}=42$.

- $D=0.0$ (assumed for all the rock mass, see Section 3).

- Unconfined compressive strength (intact rock), $\sigma_{\mathrm{ci}}=77.7 \mathrm{MPa}$.

- Hoek-Brown constant, $m_{i}=10$.

This slope problem corresponds to the very same slope case discussed already in previous sections (see points $E$ and $E^{\prime}$ in Figures $4 b$ and $5 b$, respectively; Case 3 in Tables 1 and 2; Figures $8 \mathrm{a}$ and $8 \mathrm{~b}$ ).

The FS for the slope and the critical circular failure surface were already estimated to be as follows (Sections 4, 5 and 6):

- $\mathrm{FS}=2.01$.

- Abscissa of the centre of the critical circular failure surface, $x_{c}=-207.28 \mathrm{~m}$.

- Ordinate of the centre of the critical circular failure surface, $y_{c}=586.53 \mathrm{~m}$.

- Radius of the critical circular failure surface, $R=622.08 \mathrm{~m}$.

To confirm the validity of these results, a section of the slope shown in Figure 9 was solved with the software SLIDE (Rocscience Inc. 2018), in one instance considering the slope face with the actual benches, and in the other instance considering a planar face linking the toe and crest of the slope.

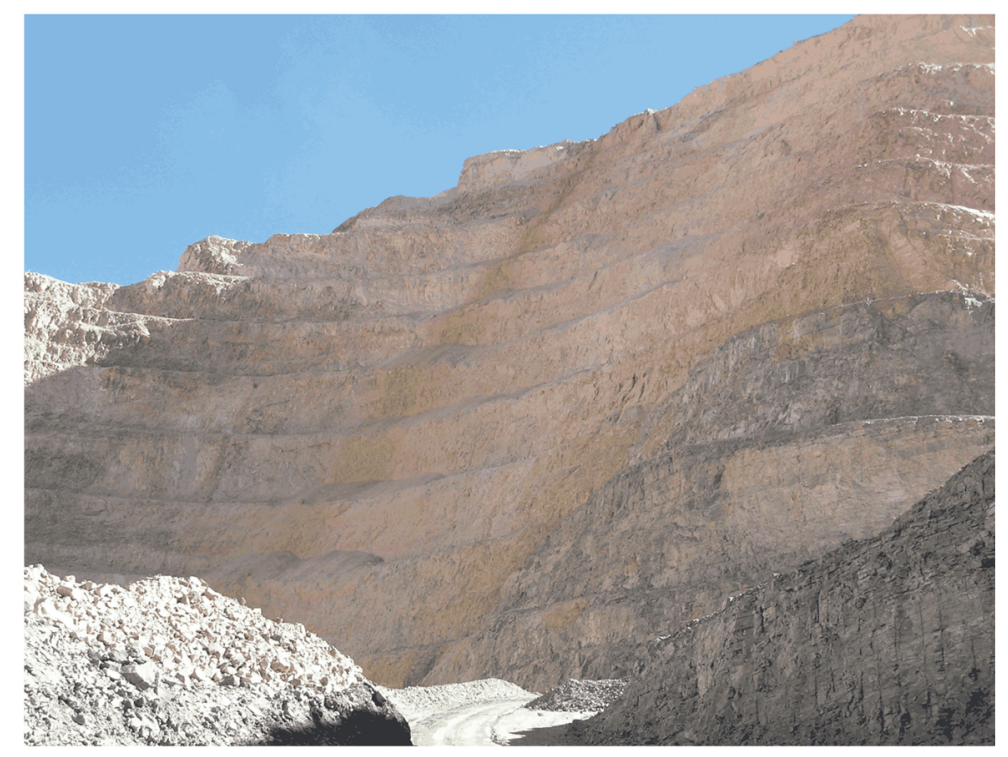

Figure 9 View of a benched slope in an open pit mine used to illustrate the application of the computational tools for stability analysis presented in this paper

Figure 10 shows a view of the results obtained with the software SLIDE for the first case in which benches were considered. The figure includes the different circular failure surfaces analysed with the software, using the same procedure for locating the critical circular failure surface discussed in Appendix A. Figure 10 shows the critical circular failure surface corresponding to the minimum FS for the slope. This is indicated with a thick 
continuum line. The FS obtained with the software (for the case of slope with benches) is 2.05 . Figure 10 also shows the location of the critical failure surface obtained with the software SLIDE and with the Excel workbook discussed in Section 6, which considers the slope face to be planar. This is indicated with a dashed line in Figure 10. For this case, the FS computed with both SLIDE and the Excel workbook is 2.01.

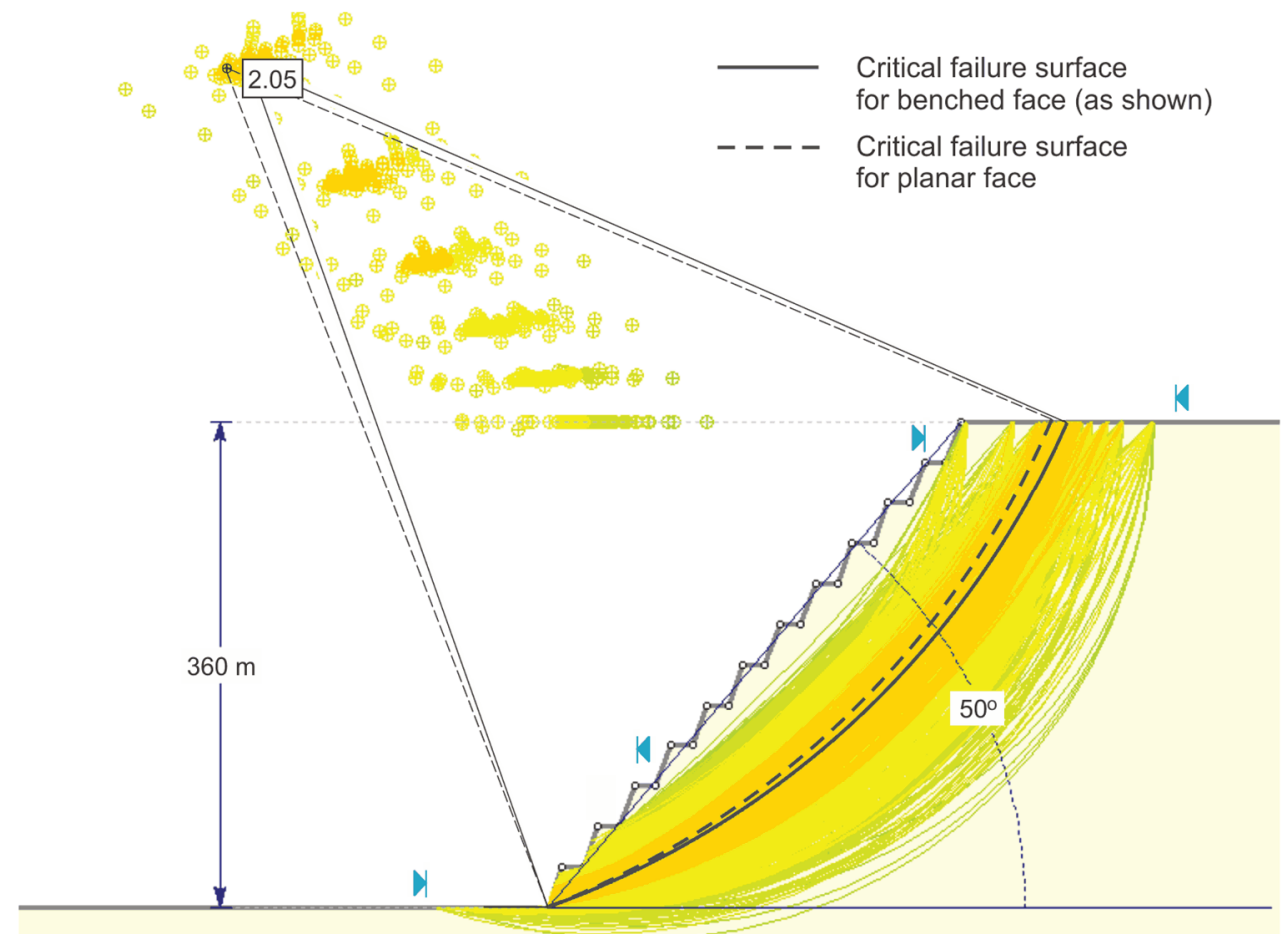

Figure 10 View of the SLIDE (Rocscience Inc. 2018) limit equilibrium model of the section of benched slope shown in Figure 9

\section{$8 \quad$ Final comments}

The computational tools presented in this paper, including dimensionless graphical representations, Excel workbook and regression equations, can be used to make quick estimations of FS and critical circular failure surface location for simple slopes excavated in dry rock masses that satisfy the Hoek-Brown failure criterion. Application of the proposed tools could be useful in the stage of pre-design of projects involving slopes in rock masses, when different slope angles or heights, or different rock mass properties need to be evaluated. It must be emphasised that the applicability of the tools presented in this paper is conditioned by the scale of the slope in relation to the degree of jointing in the rock mass, i.e. on the applicability of the Hoek-Brown failure criterion to the rock mass and on the assumption of a rotational circular type of failure for the slope (see, for example, Hoek \& Brown 2019 and Wyllie 2018, respectively). The computational tools could also be useful when performing probability and reliability analyses of stability of slopes using the Monte-Carlo simulation technique or alternative techniques such as Bayesian approaches. In such cases, thousands of cases need to be analysed to estimate FS for different input parameters and computational tools that allow quick estimation of FS are desirable (e.g. Juang et al. 1998; Wang et al. 2013; Contreras \& Brown 2018, 2019; Lacasse et al. 2019).

The implementation of the transformed version of the Hoek-Brown failure criterion discussed in Section 2 allowed the number of input variables in the problem to be reduced and consequently, a compact representation of results to be produced. Not having used the transformed version of the Hoek-Brown failure criterion would have required the need of computing an impractical number of limit equilibrium models for the development of the computational tools presented in this paper.

It needs to be emphasised that the adoption of the limit equilibrium method and the Bishop formulation used to develop the computational tools was due to efficiency reasons only, i.e. to be able to generate and compute 
the required thousands of models, in a reasonable amount of time. Similar representations could have been developed with limit analysis and/or shear strength reduction methods, as discussed in Carranza-Torres \& Hormazabal (2018). For the simple slope cases addressed in this paper (i.e. slopes with planar face in a homogeneous Hoek-Brown rock mass), no significant differences in values of FS or location of the critical failure surface could be expected when applying limit equilibrium and other methods, for example, the shear strength reduction technique (e.g. Yu et al. 1998; Dawnson et al. 1999; Cheng et al. 2007; Leshchinsky 2013). In this regard, Hammah et al. (2005) showed that results obtained with the Bishop method in SLIDE (Rocscience Inc. 2018) and with the strength reduction technique implemented in the finite element software RS2 (Rocscience Inc. 2019), in the case of simple slopes in Hoek-Brown rock masses, are similar, i.e. the methods yield similar values of FS and location of the critical failure surface. Indeed, the similarity of FS obtained with the strength reduction technique was confirmed by the authors when solving the example case described in Section 4. For space reasons, the comparison is not included in this paper. In any case, due to the non-existence of a rigorous closed-form solution for the problem of computing the FS and location of the critical failure surface of a slope in a Hoek-Brown rock mass, all of the methods available to carry out stability analyses (i.e. limit equilibrium, shear strength reduction technique, etc.) can be expected to give an approximate solution of the problem only.

Finally, because the results obtained with the computational tools in this paper are approximate in nature, caution must be exercised when applying these tools. In the context of using the limit equilibrium method as done in this paper, the approximate nature of the results can be further explained by the fact that slightly different values of FS and/or slightly different failure surface locations could result from application of limit equilibrium (SLIDE) models if they are re-evaluated with other methods of FS computation (e.g. different from the Bishop method), or different critical search method (e.g. other than the 'Autorefine Search' method) or with model parameters other than the ones used to generate the computational tools in this paper, as described in detail in Appendix A. In every case, when these tools are applied in preliminary and subsequent design stages of slopes in rock masses, it is recommended to always carry out further validation of the stability conditions with additional stability analysis methods, keeping in mind that numerical models are only tools to aid in the design process. These computational tools should not be a substitute for sound engineering judgement and experience.

\section{Downloading the computational tools presented in this paper}

The full set of dimensionless diagrams similar to those presented in Figures 4 and 5, generated as part of this study (i.e. diagrams corresponding to all values of dimensionless factors $Y$ listed in Section 4), have been compiled into a single Excel workbook that can be freely downloaded from the first author's website, at https://www.d.umn.edu/ carranza/SLOPE20/

The Excel file corresponding to the workbook presented in Section 6 (see Figure 8), can also be freely downloaded from the internet address above.

\section{Acknowledgement}

The authors thank Dr Evert Hoek and Dr Ted Brown (Figure 11) for the critical review and recommendations for improvement provided during the development of this paper. The authors also dedicate this paper to Dr Hoek and Dr Brown. The shear strength failure criterion for intact rock and rock masses that they introduced 40 years ago has been of paramount importance in improving the way in which surface and underground excavations in rock are designed nowadays. 


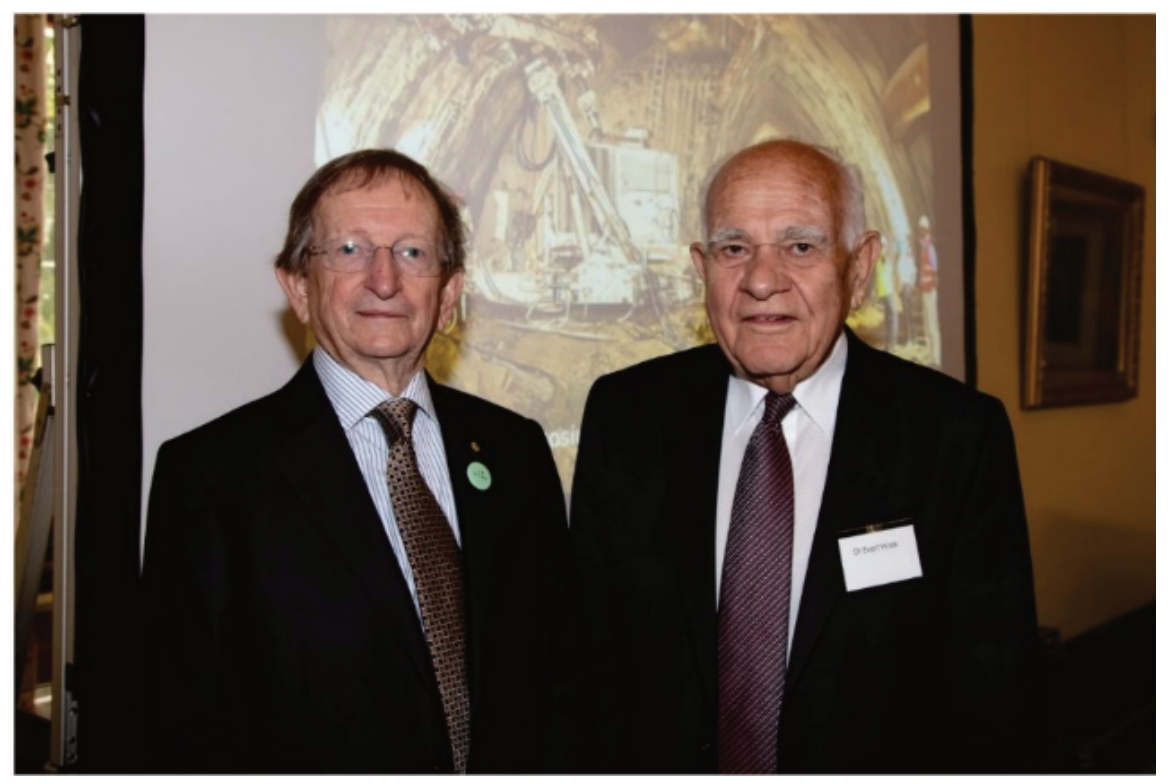

Figure 11 Dr Evert Hoek (right) and Dr Ted Brown (left) during the colloquium held at the Queensland Club in Brisbane in December 2018 to celebrate Dr Brown's 80th birthday and his professional retirement

\section{Appendix A: Limit equilibrium slope models used to construct the dimensionless functions of slope stability}

This appendix provides details of the 60,984 slope cases solved with the software SLIDE (Rocscience Inc. 2018), used to produce the dimensionless graphical representations and the Excel workbook presented in Section 6.

For most practical problems, the ranges of values of the factors $X$ and $Y$ (Equations 12 and 13) were established to be in the interval $10^{-4}$ to 100 and 0 to $10^{-1}$, respectively. These ranges were evaluated by means of a Monte-Carlo simulation that computed the factors $X$ and $Y$ for thousands of non-correlated random values generated from a uniform distribution, for the following ranges of slope height and rock mass properties:

- Slope height, $\mathrm{H}=10 \mathrm{~m}$ to $1,000 \mathrm{~m}$.

- Unit weight of the rock mass, $\gamma=20 \mathrm{kN} / \mathrm{m}^{3}$ to $27 \mathrm{kN} / \mathrm{m}^{3}$.

- Unconfined compressive strength, $\sigma_{\mathrm{ci}}=1 \mathrm{MPa}$ to $250 \mathrm{MPa}$.

- $\mathrm{GSI}=10$ to 100 .

- $\mathrm{D}=0$ (see Section 3).

- Hoek-Brown constant, $m_{i}=5$ to 40 .

As mentioned in the main text, the input variables in the models were chosen to obtain 121 equally spaced (in logarithm base-10 scale) slope cases with the factor $X$ ranging between $10^{-4}$ and 100 . Also, cases were chosen to obtain a total of 14 values of the factor $Y$, with a minimum value of zero, followed by values of $1 \times 10^{-5}$, $2.5 \times 10^{-5}, 5.0 \times 10^{-5}, 1 \times 10^{-4}$, etc. up to a maximum value of 0.1 . Slope angles $(\alpha)$ between 20 and $70^{\circ}$, in increments of $10^{\circ}$, were considered.

The total number of solved cases mentioned above (i.e. 60,984 ) is obtained by multiplying the number of values considered for the variables $X, Y$ and $\alpha(121,14$ and 6 , respectively), considering also that for each combination of values, three different sets of models, with randomly generated variables $H, \gamma, \sigma_{c i}, m_{b}$ and $s$, leading to the very same values of $X$ and $Y$, were evaluated. In addition, and as described below, the critical failure surface was searched in two stages (every model was computed twice). Therefore, the total number of solved cases resulted to be $2 \times 3 \times 121 \times 14 \times 6=60,984$. In regard to the three different sets of models with randomly generated variables mentioned above, although these cases gave mostly similar results 
of FS and scaled coordinates of points defining the critical failure surface (see Equations 14 to 19), some minor differences in results were also observed. These differences were interpreted to be due to round-off errors, associated with the relatively small values of the Hoek-Brown parameters $m_{b}$ and $s$, compared with the larger values of the other input variables. Computing the three different sets of models for each $X$ and $Y$ values allowed consistency in the results to be checked and a statistical mean of results to be determined. Each SLIDE model was constructed using the following geometrical characteristics. Denoting the length of the slope face as $L$, the left and right boundaries of the slope model were both located at a horizontal distance of $5 L$ from the toe and crest of the slope, respectively. The lower boundary of the model was located at a vertical distance of $2.5 \mathrm{~L}$ from the toe of the slope.

The FS was computed using the Bishop method of slices implemented in the software SLIDE, assuming 50 slices above the failure surface, and FS tolerance of 0.005 (with a maximum of 75 iterations) in the iterative implementation of the method.

The search process of the critical circular failure surface was done using the 'Autorefine Search' option implemented in SLIDE (the documentation of the software states that this method is the most efficient search method currently available in the software), using default input parameters (i.e. divisions along slope, circles per division, and number of iterations, all equal to 10; divisions in next iteration equal $50 \%$ ). As mentioned earlier, the search process was performed in two stages. In the first stage, the 'Autorefine Search' option was applied to the full upper surface of the model. In the second stage, the search was limited to intervals for the starting and ending points of the critical failure surface (points $A$ and $B$, respectively, in Figure 3), centred around the starting and ending points for the critical failure surface obtained in the first stage. In this more localised search, the search intervals for starting and ending points of the failure surface both had a length of $50 \%$ the height of the slope (for example, Figure 10 shows the second stage of searching of the critical failure surface. Note that the length of each of the search segments defined by the 'triangular' marks near the toe and crest of the slope is $50 \%$ the height of the slope).

The results obtained with the software SLIDE allowed the functions $\mathrm{f}_{F S}, \mathrm{f}_{x_{c}}, \mathrm{f}_{y_{c}}$ and $\mathrm{f}_{x_{A}}$ (Equations 14 to 17) to be defined. Although the function $\mathrm{f}_{F S}$ resulted smooth enough to be tabulated and used directly in the interpolation scheme implemented in the Excel workbook described in Section 6, the functions $\mathrm{f}_{x_{c}}, \mathrm{f}_{y_{c}}$ and $\mathrm{f}_{x_{A}}$, when plotted in terms of the dimensionless factor $X$ for the different values of variables $Y$ and $\alpha$, showed a discontinuous behaviour. The 'jumps' displayed by the mentioned functions were interpreted to be related to the way in which the 'Autorefine Search' option implemented in the software SLIDE works. Indeed, similar (in shape and length) arcs of circular failure surfaces can be constructed by shifting considerably the location of the centre of the circular surface and the position of the starting point of the circular failure surface near the toe of the slope. For example, the different 'clouds' of circle centres shown in Figure 10, on average, do have rather different values of coordinates $x$ and $y$. Nevertheless, some points located in different 'clouds' do have quite similar values of FS because the resulting shape and length of the arc of circle cutting the slope is similar. To simplify the interpolation process in the Excel spreadsheet presented in Section 6, the jumps displayed by the functions $\mathrm{f}_{x_{c}}, \mathrm{f}_{y_{c}}$ and $\mathrm{f}_{x_{A}}$ were smoothed using a local regression filtering algorithm known as locally estimated scatter plot smoothing (LOESS) - see Cleveland \& Loader (1996). When applying the LOESS algorithm, a recommended value of $75 \%$ for the size of the neighbourhood coefficient was used. Although the 'filtered' functions resulted smooth enough to be implemented in the interpolation algorithm used in the Excel workbook, differences in the values of $x_{C} / H$ and $y_{C} / H$ results given by the Excel workbook (with respect to the original SLIDE results) can be expected. Despite these differences in coordinates, the shape and depth of the critical circular failure surface cutting the slope should still be similar to the one originally obtained with the software SLIDE.

Finally, in regard to to the circular shape of the failure surface adopted for this study (Figure 3), some authors have proposed using log-spiral failure surfaces because such surfaces yield lower values of FS compared with circular ones (Michalowski 2002; Michalowski 2013; Utili 2013; Utili \& Abd 2016). The reason for adopting circular failure surfaces in this paper is that the commercial limit equilibrium software SLIDE (Rocscience Inc. 2018), used to develop the computational tools, does not implement log-spiral failure surfaces. 


\section{Appendix B Equations for the estimation of a conservative Factor of Safety for slopes in Hoek-Brown rock masses}

When the parameter $s$ in the Hoek-Brown shear failure criterion (Equation 1) is taken to be equal to zero, the failure criterion becomes:

$$
\sigma_{1}=\sigma_{3}+\sigma_{c i}\left(m_{b} \frac{\sigma_{3}}{\sigma_{c i}}\right)^{a}
$$

With all other variables on the right side of Equation B-1 being the same, the major principal stress $\left(\sigma_{1}\right)$ predicted by this equation will be always smaller than the one predicted by Equation 1 . This implies that for the problem of determining the FS of slopes in Hoek-Brown rock masses, consideration of $s$ equal to zero, and consequently $Y=0$ (see Equation 13), will lead to a conservative value of FS for the slope.

As mentioned in Section 4, a multiple regression analysis of the dimensionless representation of FS in Figure $5 \mathrm{~b}$ has allowed closed-form equations for this conservative FS to be obtained. This appendix presents details of the regression analysis.

The method of minimisation of the sum of square of the estimate residuals (Chapra \& Canale 2015) was used to compute a 'best fit' function to predict the FS for the case $Y=0$, as represented in Figure $5 \mathrm{~b}$. The chosen fitting equation is the following polynomial function (in logarithmic base-10 scale) of the variables $X$ and $\alpha$ :

$$
F S(X, \alpha)=10^{f_{0}(\alpha)+f_{1}(\alpha) \log (X)+f_{2}(\alpha) \log (X)^{2}+f_{3}(\alpha) \log (X)^{3}+f_{4}(\alpha) \log (X)^{4}}
$$

In Equation B-2, the functions $f_{0}, f_{1}, f_{2}, f_{3}$ and $f_{4}$ are taken to be cubic polynomials of the slope angle $\alpha$, with a discontinuous first and higher derivatives at $\alpha=50^{\circ}$. These functions were found to be as follows: If $\alpha \leq 50^{\circ}$

$$
\begin{aligned}
& f_{0}(\alpha)=-3.561 \times 10^{-2}-9.200 \times 10^{-3}(\alpha-50)-2.489 \times 10^{-5}(\alpha-50)^{2}-2.439 \times 10^{-6}(\alpha-50)^{3} \\
& f_{1}(\alpha)=-3.399 \times 10^{-1}+8.766 \times 10^{-4}(\alpha-50)+2.611 \times 10^{-6}(\alpha-50)^{2}+3.440 \times 10^{-7}(\alpha-50)^{3} \\
& f_{2}(\alpha)=-3.288 \times 10^{-2}+3.130 \times 10^{-5}(\alpha-50)-3.130 \times 10^{-6}(\alpha-50)^{2}-5.646 \times 10^{-8}(\alpha-50)^{3} \\
& f_{3}(\alpha)=-3.837 \times 10^{-3}-7.899 \times 10^{-5}(\alpha-50)-1.126 \times 10^{-6}(\alpha-50)^{2}-5.010 \times 10^{-8}(\alpha-50)^{3} \\
& f_{4}(\alpha)=4.268 \times 10^{-5}-1.383 \times 10^{-5}(\alpha-50)-1.307 \times 10^{-7}(\alpha-50)^{2}-7.198 \times 10^{-9}(\alpha-50)^{3}
\end{aligned}
$$

If $\alpha \geq 50^{\circ}$

$$
\begin{aligned}
& f_{0}(\alpha)=-3.561 \times 10^{-2}-9.092 \times 10^{-3}(\alpha-50)-2.465 \times 10^{-6}(\alpha-50)^{2}-1.280 \times 10^{-6}(\alpha-50)^{3} \\
& f_{1}(\alpha)=-3.399 \times 10^{-1}+7.524 \times 10^{-4}(\alpha-50)-3.361 \times 10^{-6}(\alpha-50)^{2}+9.897 \times 10^{-7}(\alpha-50)^{3} \\
& f_{2}(\alpha)=-3.288 \times 10^{-2}+9.853 \times 10^{-5}(\alpha-50)+2.177 \times 10^{-6}(\alpha-50)^{2}-1.980 \times 10^{-7}(\alpha-50)^{3} \\
& f_{3}(\alpha)=-3.837 \times 10^{-3}-2.470 \times 10^{-5}(\alpha-50)+2.392 \times 10^{-6}(\alpha-50)^{2}-2.413 \times 10^{-7}(\alpha-50)^{3} \\
& f_{4}(\alpha)=4.268 \times 10^{-5}-5.531 \times 10^{-6}(\alpha-50)+4.533 \times 10^{-7}(\alpha-50)^{2}-3.182 \times 10^{-8}(\alpha-50)^{3}
\end{aligned}
$$

It is important to remark that the regression analysis was done considering that the slope inclination angle $\alpha$ in Equations B-2 to B-4 is expressed in degrees and not in radians (e.g. when using these equations to compute the FS for a slope with inclination angle $45^{\circ}$, the equations must consider the variable $\alpha$ to be 45 and not $\pi / 4$ ).

As with any regression analysis, application of Equations B-2 to B-4 to compute the FS can be expected to show some error with respect to the original results obtained with the SLIDE models. This error, which is an intrinsic consequence of the fitting process, will be shown next to be within $\pm 2 \%$.

Figure B-1 includes similar representation as in Figure 5b, but obtained with the Equations B-2 to B-4. At first sight, the diagrams in Figures B-1 and $5 b$ are identical. Nevertheless, and as mentioned above, there is some error associated with the application of Equations B-2 to B-4. 
To quantify this error, the dimensionless representation of the FS given by Equation 14 (with the function $f_{F S}$ as represented in Figure $5 b$ ) is assumed to be the 'true' solution of the problem. In such a case, the absolute error can be computed as follows:

$$
\text { FS Error [\%] }=\frac{\text { FS (with Eq. (B-2)) - FS (with Eq. (14)) }}{\text { FS (with Eq. (14)) }}
$$

Figure B-2 is the graphical representation of Equation B-5. The figure shows that the error associated with application of Equations B-2 to B-4 can be positive or negative (i.e. the scaled factors of safety can be either overestimated or underestimated, respectively), and that for all cases of factors $X$ and angles $\alpha$ considered in this study, the absolute value of the error is smaller than $2 \%$. In any case, the authors recommend caution when applying Equations B-2 to B-4 because of the mentioned error associated with the fitting process. Also, and as discussed in Section 8, the limit equilibrium results from which these equations have been derived are understood to be approximate in nature, in view that there is no exact (or closed-form) solution for the problem introduced in Section 3 (Carranza-Torres \& Hormazabal 2018).

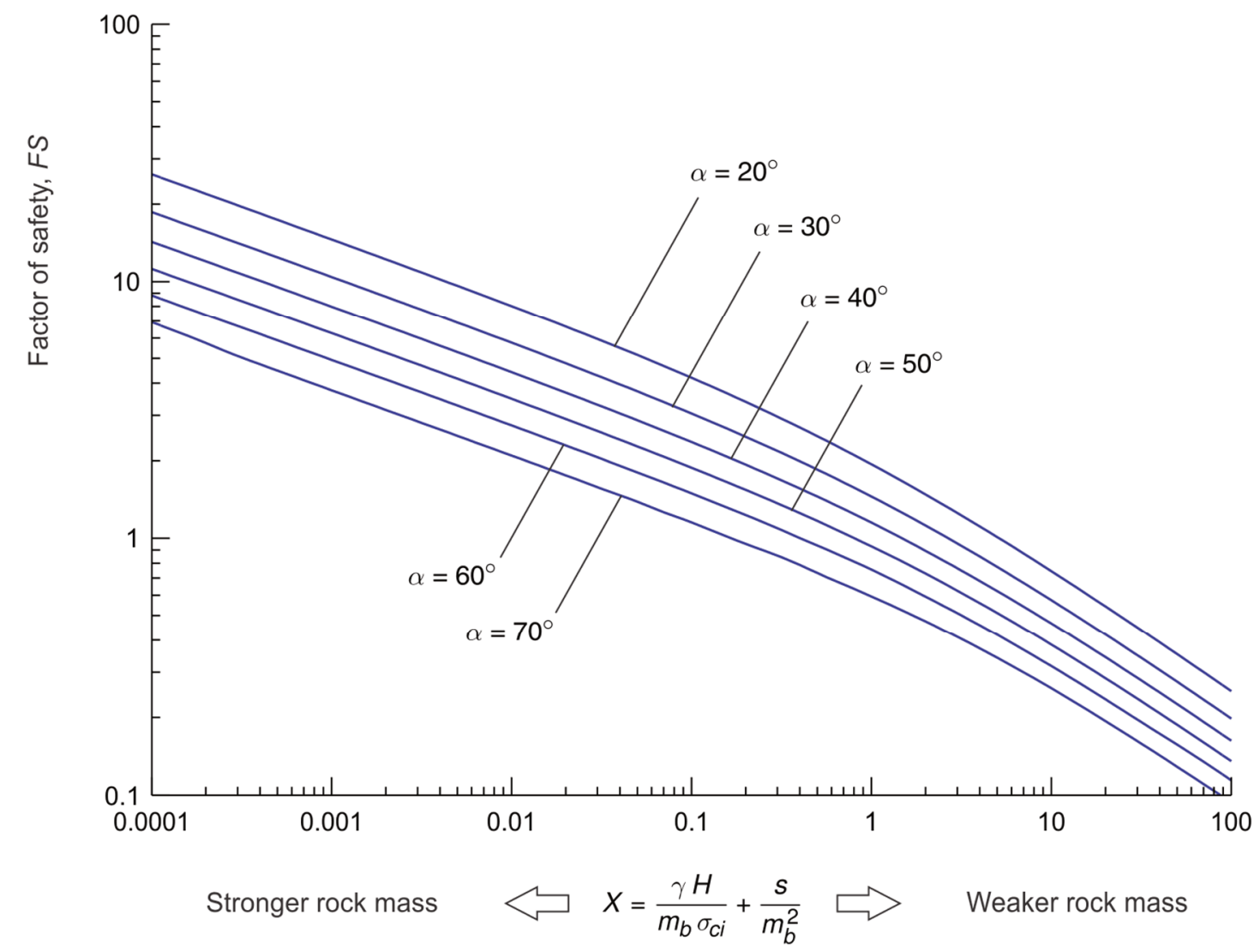

Figure B-1 Dimensionless stability diagram for the estimation of the Factor of Safety obtained with Equations B-2 to B-4. This representation, which is equivalent to that in Figure $5 b$, is valid for the case $\mathbf{Y}=\mathbf{s} / \mathbf{m}_{\mathbf{b}}^{2}=\mathbf{0}$ 


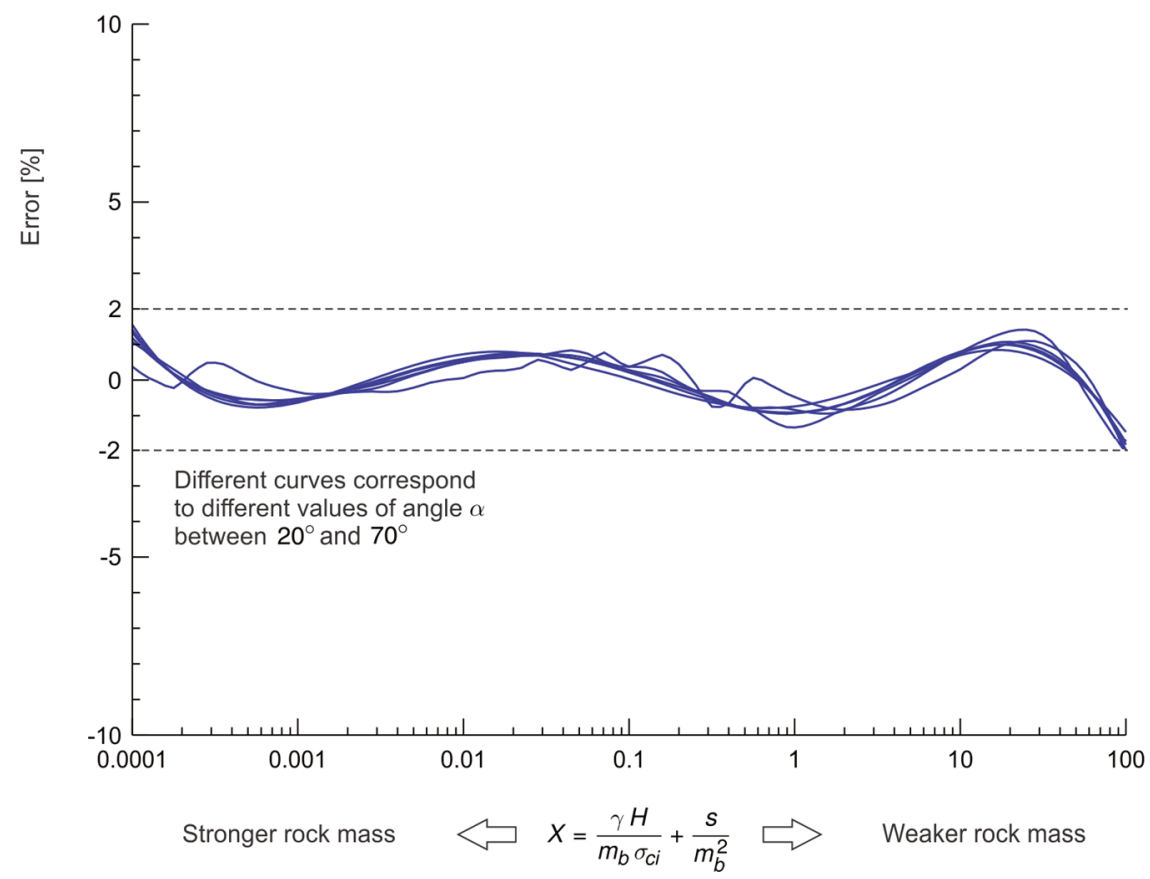

Figure B-2 Graphical representation of Factor of Safety error computed with Equation B-5

\section{References}

Abramson, LW, Lee, TS, Sharma, S \& Boyce, GM 2002, Slope stability and stabilisation methods, 2nd edn, John Wiley \& Sons, New York.

Balmer, G 1952, 'A general analytical solution for Mohr's envelope', American Society for Testing Materials, vol. 52, pp. $1260-1271$.

Bishop, AW 1955, 'The use of the slip circle in the stability analysis of slopes', Geotechnique, vol. 5, issue 1, pp. 7-17.

Carranza-Torres, C 2004, 'Some comments on the application of the Hoek-Brown failure criterion for intact rock and rock masses to the solution of tunnel and slope problems', in G Barla \& M Barla (eds), Proceedings of the X Conference on Rock and Engineering Mechanics, Politecnico di Torino, Turin, pp. 285-326.

Carranza-Torres, C \& Fairhurst, C 1999, 'The elasto-plastic response of underground excavations in rock masses that satisfy the HoekBrown failure criterion', International Journal of Rock Mechanics and Mining Sciences, vol. 36, issue 8, pp. 777-809.

Carranza-Torres, C \& Fairhurst, C 2000, 'Application of the convergence-confinement method of tunnel design to rock masses that satisfy the Hoek-Brown failure criterion', Tunneling and Underground Space Technology, vol. 15, issue 2, pp. $187-213$.

Carranza-Torres, C \& Hormazabal, E 2018, 'Computational tools for the determination of factor of safety and location of the critical failure surface for slopes in Mohr-Coulomb dry ground', Proceedings of the 2018 International Symposium on Slope Stability in Open Pit Mining and Civil Engineering, Asociacion Nacional de Ingenieros de Minas, Sevilla, https://www.d.umn.edu/ carranza/SLOPE18/

Carter, T \& Carranza-Torres, C 2019, 'Global characterization of high rock slopes using the Hoek-Brown mb parameter as controlling index', Proceedings of the 14th International Congress on Rock Mechanics and Rock Engineering, Foz do Iguassu.

Chapra, SC \& Canale, RP 2015, Numerical methods for engineers, 7th edn, Mc Graw Hill, New York.

Cheng, YM, Lansivaara, T \& Wei, WB 2007, 'Two-dimensional slope stability analysis by limit equilibrium and strength reduction methods', Computers and Geotechnics, vol. 34, issue 3, pp. 137-150.

Cleveland, WS \& Loader, C 1996, 'Smoothing by local regression: Principles and methods', in W Hardle \& M Schimek (eds), Statistical theory and computational aspects of smoothing, Springer-Verlag Berlin and Heidelberg Gmbh \& Co. Kg, Berlin, pp. 10-49.

Contreras, LF \& Brown, ET 2018, 'Bayesian inference of geotechnical parameters for slope reliability analysis', Proceedings of the 2018 International Symposium on Slope Stability in Open Pit Mining and Civil Engineering, Asociacion Nacional de Ingenieros de Minas, Sevilla.

Contreras, LF \& Brown, ET 2019, 'Slope reliability and back analysis of failure with geotechnical parameters estimated using Bayesian inference', Journal of Rock Mechanics and Geotechnical Engineering, vol. 11, issue 3, pp. 628-643.

Dawnson, EM, Roth, WH \& Drescher, A 1999, 'Slope stability analysis by strength reduction', Geotechnique, vol. 49, issue 6 , pp. 835-840.

Dawson, E, You, K \& Park, Y 2000, 'Strength-reduction stability analysis of rock slopes using the Hoek-Brown failure criterion', Proceedings of Geo-Denver 2000. Volume: Trends in Rock Mechanics, American Society of Civil Engineers, Reston, pp. 65-77.

de Bruyn, I, Coulthard, M, Baczynski, N \& Mylvaganam, J 2013, 'Two-dimensional and three-dimensional distinct element numerical stability analyses for assessment of the west wall cutback design at Ok Tedi Mine, Papua New Guinea', in PM Dight (ed.), Proceedings of the 2013 International Symposium on Slope Stability in Open Pit Mining and Civil Engineering, Australian Centre for Geomechanics, Perth, pp. 653-668, https://doi.org/10.36487/ACG_rep/1308_43_deBruyn 
Hammah, RE, Yacoub, TE, Corkum, BC \& Curran, JH 2005, 'The shear strength reduction method for the generalized Hoek-Brown criterion', Proceedings of the 40th US Rock Mechanics Symposium: Rock Mechanics for Energy, Mineral and Infrastructure Development in the Northern Regions, American Rock Mechanics Association, Alexandria.

Hoek, E \& Bray, J 1974, Rock slope engineering, 1st edn, Institution of Mining and Metallurgy, London.

Hoek, E \& Bray, J 1977, Rock slope engineering, 2nd edn, Institution of Mining and Metallurgy, London.

Hoek, E \& Bray, J 1981, Rock slope engineering, 3rd edn, Institution of Mining and Metallurgy, London.

Hoek, E \& Brown, ET 1980, 'Empirical strength criterion for rock masses', Journal of the Geotechnical Engineering Division, vol. 106, issue GT9, pp. 1013-1035.

Hoek, E \& Brown, ET 1997, 'Practical estimates of rock mass strength', International Journal of Rock Mechanics and Mining Sciences, vol. 34, issue 8, pp. 1165-1186.

Hoek, E \& Brown, ET 2019, 'The Hoek-Brown failure criterion and GSI - 2018 edition', Journal of Rock Mechanics and Geotechnical Engineering, vol. 11, issue 3, pp. 445-463.

Hoek, E, Carranza-Torres, C \& Corkum, B 2002, 'Hoek-Brown failure criterion - 2002 edition', Proceedings of the 5th North American Rock Mechanics Symposium and the 17th Tunnelling Association of Canada Conference, Toronto, pp. 267-273.

Hoek, E \& Karzulovic, A 2000, 'Rock-mass properties for surface mines', in WA Hustrulid, MK McCarter \& DJA van Zyl (eds), Proceedings of the Slope Stability in Surface Mining, Society for Mining, Metallurgical and Exploration, Littleton, pp. 59-67.

Hormazabal, E, Rovira, F, Walker, M \& Carranza-Torres, C 2009, Analysis and design of slopes for Rajo Sur, an open pit mine next to the subsidence crater of El Teniente mine in Chile, Proceedings of the 2009 International Symposium on Slope Stability in Open Pit Mining and Civil Engineering, University de los Andes, Santiago, https://www.srk.com/ sites/default/files/file/EHormazabal-MWalker-CCarranza-Torres_Analysis_Design_of_Slopes_for_Rajo_Sur_2009_0.pdf

Jiang, X, Cui, P \& Liu, C 2016, 'A chart-based seismic stability analysis method for rock slopes using Hoek-Brown failure criterion', Engineering Geology, vol. 209, pp. 196-208.

Juang, CH, Jhi, YY \& Lee, DH 1998, 'Stability analysis of existing slopes considering uncertainty', Engineering Geology, vol. 49, issue 2, pp. 111-122.

Kotze, G \& Bosman, J 2015, 'Towards expediting large-scale slope design using a re-worked design chart as derived from limit equilibrium methods', in TR Stacey (ed.), Proceedings of the 2015 International Symposium on Slope Stability in Open Pit Mining and Civil Engineering, The Southern African Institute of Mining and Metallurgy, Johannesburg, pp. 341-362.

Lacasse, S, Nadim, F, Liu, ZQ, Eidsvig, UK, Le, TMH \& Lin, CG 2019, 'Risk assessment and dams. Recent developments and applications', Proceedings of the XVII European Conference on Soil Mechanics and Geotechnical Engineering, Icelandic Geotechnical Society, Reykjavik, https://www.ecsmge-2019.com/uploads/2/1/7/9/21790806/k1-1110-ecsmge-2019-keynote_lacasse.pdf

Leshchinsky, B 2013, 'Comparison of limit equilibrium and limit analysis for complex slopes', in C Meehan, D Pradel, MA Pando \& JF Labuz (eds), Geo-Congress 2013: Stability and Performance of Slopes and Embankments III, American Society of Civil Engineers, Reston, pp. 1280-1289.

Li, AJ, Merifield, RS \& Lyamin, AV 2008, 'Stability charts for rock slopes based on the Hoek-Brown failure criterion', International Journal of Rock Mechanics and Mining Sciences, vol. 45, issue 5, pp. 689-700.

Londe, P 1988, 'Discussion on the paper 'Determination of the shear stress failure in rock masses' by R Ucar', Journal of the Geotechnical Engineering Division, vol. 112, no.3, pp. 374-376.

Michalowski, RL 2002, 'Stability charts for uniform slopes', Journal of Geotechnical and Geoenvironmental Engineering, vol. 128-4, issue GT9, pp. 351-355.

Michalowski, RL 2013,' Stability assessment of slopes with cracks using limit analysis', Canadian Geotechnical Journal, vol. 50, pp. 1011-1021.

Nekouei, AM \& Ahangari, K 2013, 'Validation of Hoek-Brown failure criterion charts for rock slopes', International Journal of Mining Science and Technology, vol. 23, issue 6, pp. 805-808.

Read, J \& Stacey, P 2009, Guidelines for open pit slope design, CSIRO Publishing, Melbourne.

Rocscience Inc. 2018, SLIDE, computer software, Rocscience, Toronto.

Rocscience Inc. 2019, RS2, Rocscience, Toronto.

Rose, N, Scholz, M, Burden, J, King, M, Maggs, C \& Havaej, M 2018, 'Quantifying transitional rock mass disturbance in open pit slopes related to mining excavation', Proceedings of the 2018 International Symposium on Slope Stability in Open Pit Mining and Civil Engineering, Asociacion Nacional de Ingenieros de Minas, Sevilla.

Shen, J, Karakus, M \& Xu, C 2013, 'Chart-based slope stability assessment using the generalized Hoek-Brown criterion', International Journal of Rock Mechanics and Mining Sciences, vol. 64, pp. 210-219.

Sun, C, Chai, J, Xu, Z, Qin, Y \& Chen, X 2016, 'Stability charts for rock mass slopes based on the Hoek-Brown strength reduction technique', Engineering Geology, vol. 214, pp. 94-106.

Utili, S 2013, 'Investigation by limit analysis on the stability of slopes with cracks', Geotechnique, vol. 6, issue 2, pp. 140-154.

Utili, S \& Abd, AH 2016, 'On the stability of fissured slopes subject to seismic action', International Journal for Numerical and Analytical Methods in Geomechanics, vol. 40, pp. 785-806.

Wang, L, Hwang, J, Juang, H \& Atamturktur, S 2013, 'Reliability-based design of rock slopes a new perspective on design robustness', Engineering Geology, vol. 154, pp. 56-63.

Wyllie, DC 2018, Rock slope engineering. Civil Applications, CRC Press, Boca Raton.

Xu, J, Pan, Q, Yang, X L \& Li, W 2017, 'Stability charts for rock slopes subjected to water drawdown based on the modified nonlinear Hoek-Brown failure criterion', International Journal of Geomechanics, vol. 18, issue 1, pp. 805-808.

Yu, HS, Salgado, R, Sloan, SW \& Kim, JM 1998, 'Limit analysis versus limit equilibrium for slope stability', Journal of Geotechnical and Geoenvironmental Engineering, vol. 124, issue 1, pp. 1-11. 